\title{
Wintertime connections between extreme wind patterns in Spain and large-scale geopotential height field
}

\author{
A. Pascual ${ }^{\text {a,* }}$, M.L. Martín ${ }^{\text {b }}$, F. Valero ${ }^{\text {a }}$, M.Y. Luna ${ }^{c}$, A. Morata $^{\mathrm{c}}$ \\ a Dpto. Astrofisica y CC. de la Atmósfera, Facultad de CC. Físicas, Universidad Complutense de Madrid, Spain \\ b Dpto. Matemática Aplicada, Escuela Universitaria de Informática, Campus María Zambrano, Universidad de Valladolid, Pza. Alto de los Leones, 1 , 40005 Segovia, Spain \\ c Agencia Estatal de Meteorología, Leonardo Prieto Castro, 8, 28040 Madrid, Spain
}

\section{A R T I C L E I N F O}

\section{Article history:}

Received 26 July 2012

Received in revised form 15 October 2012

Accepted 31 October 2012

\section{Keywords:}

Daily mean wind speed

Geopotential height

Principal component analysis

Wavelets

Composites

Wind speed cumulated probability

\begin{abstract}
A B S T R A C T
The present study is focused on the study of the variability and the most significant wind speed patterns in Spain during the winter season analyzing as well connections between the wind speed field and the geopotential height at $1000 \mathrm{hPa}$ over an Atlantic area. The daily wind speed variability is investigated by means of principal components using wind speed observations. Five main modes of variation, accounting $66 \%$ of the variance of the original data, have been identified, highlighting their differences in the Spanish wind speed behavior. Connections between the wind speeds and the large-scale atmospheric field were underlined by means of composite maps. Composite maps were built up to give an averaged atmospheric circulation associated with extreme wind speed variability in Spain. Moreover, the principal component analysis was also applied to the geopotential heights, providing relationships between the large-scale atmospheric modes and the observational local wind speeds. Such relationships are shown in terms of the cumulated frequency values of wind speed associated with the extreme scores of the obtained large-scale atmospheric modes, showing those large-scale atmospheric patterns more dominant in the wind field in Spain.
\end{abstract}

(c) 2012 Elsevier B.V. All rights reserved.

\section{Introduction}

The sustainable and clean renewable energies are been incessantly used since the last decades, arising the wind energy, among them, as a proven useful technology. Consequently, many efforts are currently leading to use high potential wind energy resources. Both wind energy generation and the associated infrastructure have the possibility of suffering great damage when destructive wind speeds associated with severe storms are observed. Winter storms are responsible for more than $50 \%$ of the total economic loss in central Europe, due to natural hazards (Ulbrich et al., 2001) and a single extreme storm event can cause economic losses exceeding 10 billion euros. Therefore, the knowledge of atmospheric circulation patterns, particularly the

\footnotetext{
* Corresponding author at: Astrofísica y CC. de la Atmósfera, Facultad de CC Físicas, Universidad Complutense de Madrid, Avda. Complutense s/n, Ciudad Universitaria, 28040 Madrid, Spain. Tel./fax: + 34913945088.

E-mail address: a.depascual@fis.ucm.es (A. Pascual).
}

one dealing with atmospheric patterns conducive to risky meteorological situations related to extreme wind events, is especially important for wind energy applications (Palutikof et al., 1987; Thuilleier, 1987; Zuranski and Jaspinka, 1996). Extreme events have been categorized taken into account damages and economic loss (Gaya et al., 2008; Amaro et al., 2009). Extremes have been also identified as their occurrence probabilities (OrtizBeviá et al., 2011); they have been analyzed from the spatial-temporal characteristics of prediction errors (Tastu et al., 2011), or taking into account their probabilistic forecasts by statistical scenarios (Pinson et al., 2009a; Pinson and Madsen, 2012), by ensemble predictions (Pinson et al., 2009b; Martín et al., 2010). The final analysis can be used for nowcasting wind power over the whole area, and for data assimilation purposes (in order to update and improve wind power predictions), or for issuing "global" warnings related to expected accuracy of weather and wind power forecasts over the area considered.

In determining temporal-spatial distribution changes of wind and other climatological elements, it is necessary to take 
into account the atmospheric circulation variability. The Western European climate steps necessarily on the available knowledge of natural variability in regional scales and its relationship to large-scale circulation (Luna et al., 2001; Valero et al., 2004; Martín et al., 2004, 2011a; García-Ortega et al., 2011; Martín et al., 2011b). The relative location of different pressure centers over the North Atlantic area influence different air masses with distinct physical characteristics over Iberia to produce a wide range of differentiated regional climates, playing the topography a leading role. In fact, at local scales the development of cloud systems or the enhancement of wind speed over different areas can be especially affected due to the topography (Frouin et al., 1990; Haynes and Barton, 1990; Bougeault et al., 1997); at large-scale domains, topography can generate to redirected synoptic and mesoscale flows (Valero et al., 1997).

The present study is focused on the study of the Spanish wind speed variability and the most significant wind speed patterns over Spain during the winter season analyzing as well connections between the wind speed field and the geopotential height at $1000 \mathrm{hPa}$ over an Atlantic area. To do this, the principal component analysis is first applied to the regional variable in order to extract their most remarkable patterns. The multivariate techniques have been successfully used by the authors (Martín et al., 2004, 2006; Morata et al., 2006; Martín et al., 2011a, 2011b) in other studies to gain a better insight into the seasonal relation between large-scale circulation anomalies and regional variable fluctuations, giving evidence of the influence of several North Atlantic teleconnection patterns of low-frequency on the variability of the regional variables in the Western Mediterranean area. An additional purpose of this paper is to analyze the linkage between the most significant daily wind speed patterns with real large-scale circulation configurations, reinforcing the results by means of cumulative probability curves and composite maps. Composites have been used by the authors in several studies in order to analyze different fields, obtaining relationships between them, so that maximum and minimum intensity phases of a field can be related to the other one (Valero et al., 2004; Martín et al., 2004, 2011a, 2011b). Here, composites are obtained from the extreme data statistically previously derived by means of the multivariate analysis.

The study is organized as follows. A brief description of the data sets and the diverse methods applied to the original data sets is given in Section 2. Section 3 is devoted to analyze the Spanish wind speed variability in terms of the spatial and temporal results obtained from the principal component analysis. As well the connections between the Iberian wind speed field and the atmospheric circulation field are also studied, offering the results from the composite maps and the wind speed cumulated probabilities obtained from the extreme statistical data previously derived. The summary of the main results is drawn in Section 4.

\section{Data and methods}

Two data sets have been used in this study: 1000 hPa daily geopotential heights at 12:00 UTC (Z1000) and daily mean wind speed (MWS) data for 21 stations distributed over Iberia (Fig. 1a) during the winter (D-J-F) season. Z1000 data are a product of the ERA40 Reanalysis (Gibson et al., 1997; Simmons and Gibson, 2000). The Z1000 data are given on a $1.2^{\circ} \times 1.2^{\circ}$ latitude $\times$ longitude grid, spanning a domain from $51.5^{\circ} \mathrm{W}$ to $15.5^{\circ} \mathrm{E}$ and $20^{\circ}$ to $60^{\circ} \mathrm{N}$ for $1971-2007$. Thus, 1995 spatial nodes or grid points for 36 years of temporal record are considered. Wind data used in this paper consists of time series of daily MWS from 21 sites irregularly distributed over the Iberian Peninsula, covering the 1970-2002 period. These wind data come from in-situ measurements of the station network of the Spanish Meteorological Service (Agencia Estatal de Meteorología, AEMET). The list of stations used and their geographical coordinates are shown in Table 1.

The Iberian wind regime exhibits important climatic contrasts. The northern Peninsula is mainly affected by cold dry or moist wind, depending on the air mass origin, while the south of Iberia is affected by the southwestern warm dry winds coming from North Africa or by warm wet air masses coming from the southeast. As an example, the Mediterranean Peninsula coastline is affected by wet winds which are called Levante or by wet and warm air masses coming from the Sahara, the Xaloc (Fig. 1b). The northwestern (southeastern) cold (warm) dry (moist) winds blowing down (up)-valley Ebro are known as Cierzo (Bochorno) while west-northwestern moist cold winds, named Galerna, blow the Cantabric coasts (Font, 2000; Garcia, 1985). On the other hand, Tramontana is northern or northeastern winds affecting Catalonia and the Balearics. Southern Iberia is influenced by winds such as Ábrego. As a result, advection of west-east air masses with diverse characteristics, influence of orography and land-sea temperature contrasts could lead to significant northernsouthern differences. Advances in understanding the relationships of winds in the Iberian Peninsula with coherent atmospheric patterns constitute an issue of relevance and a fundamental prerequisite for engineering, forestry and risk management purposes.

In order to extract the general behavior, a S-mode principal component analysis (PCA) was applied to the databases, extracting the most significant patterns from the original data (Preisendorfer, 1998; Richman, 1988). The new uncorrelated variables are called principal components (PCs) and consist on linear combinations of the original variables derived from the diagonalization of the covariance/correlation matrix. The coefficients of the linear combinations represent the weight of the original variables in the PCs and they are named loadings or PC patterns. The PCs indicate modes of variation of the original field and are numbered according with their related variance. Thus, the first PC is the linear combination with the maximum possible variance; the second one is the linear combination with the maximum possible variance which is uncorrelated with the first PC and so on. More details about PCA are found in Joliffe (1986) and Sneyers et al. (1989). The projection of the original series onto each eigenvector gives as result the time-dependence coefficient named scores or PC time series. In our case, the PCA was applied to the correlation matrices of data sets, the Z1000 and Spanish wind speed fields, giving as a result a set of eigenvalues and eigenvectors. Generally, the leading (the first ones) eigenvectors tend to describe regions with largest fluctuations. Thus, most information from the data can be represented using a noticeably small number of the principal components. The authors have studied the main characteristics in precipitation and wind fields by means of PCA (Sotillo et al., 2006; Morata et al., 2008; Valero et al., 2009; 


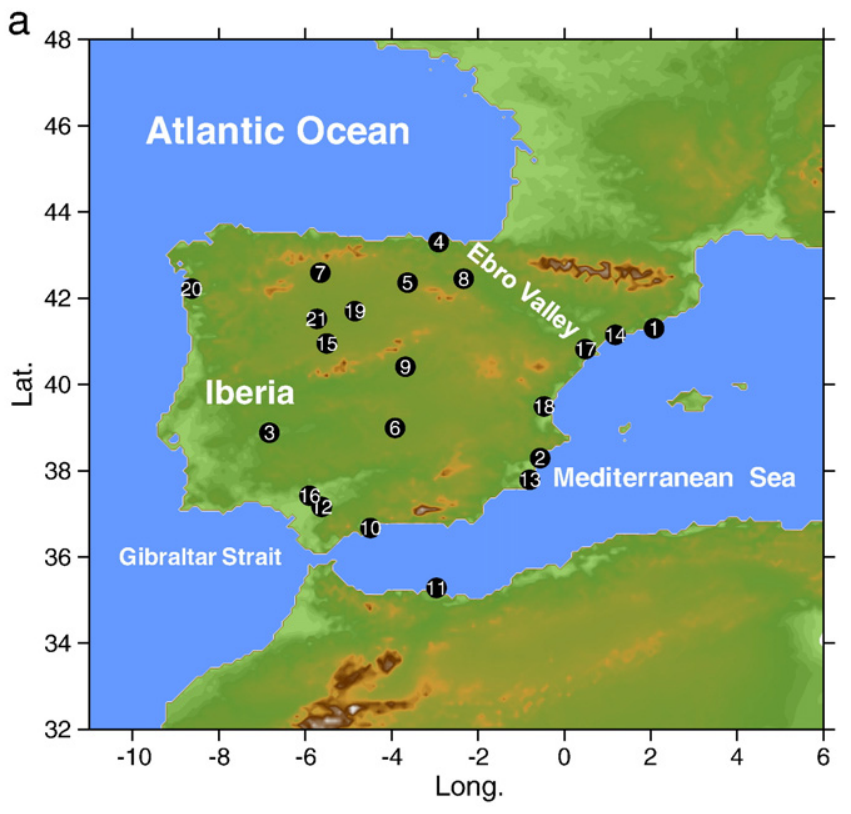

b

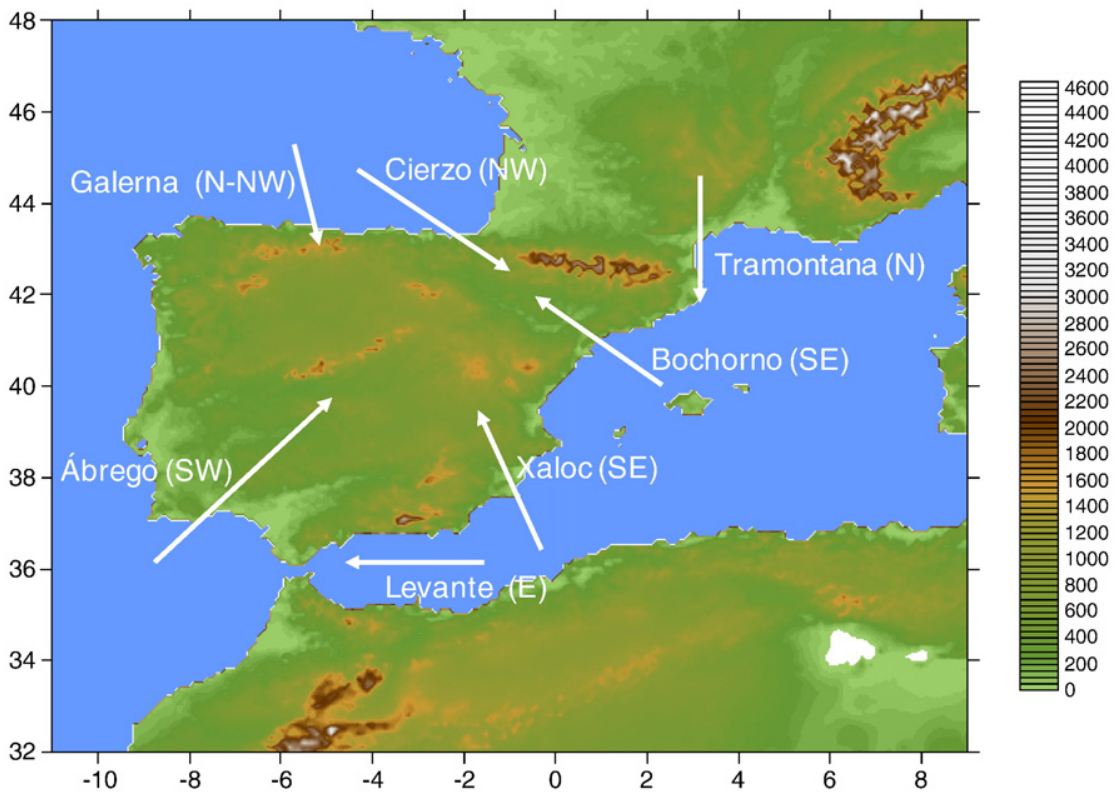

Fig. 1. (a) Circles indicate the wind stations over Spain with the Iberian Peninsula orography detailed. The station codes are shown in Table 1 . The $x$-axis corresponds to longitude, positive (negative) for degree East (West). The y-axis to latitude, positive for degree North; (b) the Iberian Peninsula with typical winds and directions superimposed.

Pascual et al., 2012) increasing the understanding about the variability of these regional variables in the Iberian Peninsula.

In order to get information of all timescales of the PC time series, a Wavelet Multiresolution Analysis has been carried out. The wavelet transform technique was introduced and formulated by Morlet et al. (1982) and Grossmand and Morlet (1984). Wavelet transforms have been applied successfully to different studies of meteorological and climatological time series in order to understand their temporal scales of variability (Mahrt, 1991; Gamage and Blumen, 1993; Weng and Lau, 1994; Gao and Li, 1993; Morata et al., 2006). These studies highlight the advantages of the technique compared with
Fourier transform analysis because of the former play down the difficulty of showing structures on different time or spatial scales at different time or spatial locations. The Fourier transform does not contain any time dependence on the signal, not providing any local information regarding the time evolution of its spectra. One of the differences with regard to the Fourier transform is that the wavelets enable localization in frequency and in time (Morlet et al., 1982; Mallat, 1998). As wavelet decomposition only uses dilatations and translations of a unique function, it is optimal in the sense of the timefrequency uncertainty principle in which the correlation between duration and average frequency is respected (Kaiser, 
Table 1

List of stations used indicating the code for Fig. 1a, name, longitude, latitude and altitude.

\begin{tabular}{llrrr}
\hline ID & Name & Lat. & Long. & Elev. \\
\hline 1 & Aeroport De Barcelona (El Prat) & 41.30 & 2.08 & 6 \\
2 & Alicante (Aeropuerto El Altet) & 38.29 & -0.56 & 31 \\
2 & Alicante (Ciudad Jardin) & 38.37 & -0.49 & 82 \\
3 & Badajoz (Talavera 'Base Aerea') & 38.88 & -6.83 & 185 \\
4 & Bilbao (Aeropuerto) & 43.30 & -2.91 & 39 \\
5 & Burgos (Villafria) & 42.36 & -3.63 & 890 \\
6 & Ciudad Real (Escuela De Magisterio) & 38.99 & -3.92 & 627 \\
7 & Leon (Virgen Del Camino) & 42.59 & -5.65 & 916 \\
8 & Logroño (Agoncillo) & 42.45 & -2.33 & 352 \\
9 & Madrid (Cuatro Vientos 'Aerodromo') & 40.38 & -3.79 & 687 \\
9 & Madrid Retiro & 40.41 & -3.68 & 667 \\
10 & Malaga (Aeropuerto) & 36.67 & -4.49 & 7 \\
11 & Melilla & 35.28 & -2.96 & 55 \\
12 & Moron De La Frontera (Base Aerea) & 37.16 & -5.62 & 87 \\
13 & Murcia (San Javier) & 37.79 & -0.80 & 2 \\
14 & Reus (Aeroport) & 41.15 & 1.18 & 68 \\
15 & Salamanca (Matacan) & 40.95 & -5.50 & 790 \\
16 & Sevilla (Aeropuerto) & 37.42 & -5.90 & 26 \\
17 & Tortosa (Obser. Del Ebro) & 40.82 & 0.49 & 48 \\
18 & Valencia (Aeropuerto Manises) & 39.49 & -0.47 & 57 \\
19 & Valladolid (Villanubla) & 41.70 & -4.85 & 846 \\
20 & Vigo (Peinador) & 42.22 & -8.63 & 255 \\
21 & Zamora (Observatorio) & 41.52 & -5.73 & 656 \\
\hline & & & &
\end{tabular}

1995). Thus, wavelets turn to be appropriate and powerful tool to study time series. The wavelet transformation has not only good local properties in time and frequency domain but also it works as a microscopic function in analysis by decomposing a time series into a set of scale components and allows discrimination between oscillations to occur at fast scales and others at slow scales (Morlet et al., 1982; Grossmand and Morlet, 1984; Morata et al., 2006, 2008; Aznar et al., 2010). Furthermore, the continuous wavelet analysis presents the advantage that it is usually easier to interpret because all the information, in terms of coefficients in frequency and in time, tends to be more visible. In this paper, the continuous wavelet (Mallat, 1998) and its marginal spectrum (Huang and Shen, 2008), built as the cumulated coefficients per frequency, were used as a filter to decompose and isolate characteristics of the fields at different frequencies. A more traditional correlation analyses based on spectral analyses and Mann-Kendall tests have also been applied to the PC time series (Goossens and Berger, 1986) as well as the wavelet analysis.

The relationship between observational patterns and the statistical modes obtained from the PCA is studied by directly constructing positive (negative) composite maps. To do this, from a number of days with the highest (lowest) values of the scores of the MWS field, several positive (negative) maps are built, highlighting the strong link between the wind speeds and the atmospheric field. If the dates associated with the highest and lowest values of the PC time series of MWS are picked up, real maps of Z1000 and also wind speeds, conditioned by those scores, will be associated with the strong positive or negative phase of the corresponding PCA mode. While the derived modes are statistically built, the composite maps represent configurations of the variable which can be comparable to observations. The choice of the number of situations has been arbitrarily chosen to be the 5 and 95 percentiles of the scores of the time series obtained from the PCA. This number of data cases is enough to be representative of the patterns linked with strong wind anomalies.

Finally, discussions about relationships between the Z1000 PCs and the observational local wind speeds are also provided in terms of the cumulated probability values of wind speed associated with the highest and lowest scores of the obtained Z1000 PC time series. These plots provide an idea about the observational wind speed frequency distributions conditioned by the different strong scores of the Z1000 PC time series.

\section{Results}

\subsection{Wind speed mode results}

As it is described in the Data and methods section, the PCs are proposed to adequately represent the original data set variation without loss of significant information. In order to give a statistical significance of the results and to indicate the genuine and not artificial result of a statistical methodology, it is necessary to analyze the statistical robustness of the obtained modes. To do this, a procedure based on a Monte Carlo approach is applied. Following in a similar way the procedure described in Martín et al. (2004, 2011a), 100 scrambled data sets are built by only destroying the chronology of the MWS field. Thus, if two strongly related data sets are scrambled, their relationship becomes worse to some extent, being reflected directly in the variance of each mode. Then, a PCA is performed over each scrambled data set, doing consequently 100 PCs, comparing the $100 \mathrm{PC}$ results with those obtained from the original unscrambled data. The observed variance (OV) from the original MWS data set is considered statistically significant at the $95 \%$ level if such observed OV is not higher than five values of the 100 scrambled data sets. If lesser than five scrambled variance values are found to be greater than the observed $\mathrm{OV}$, then the observed $\mathrm{OV}$ is significant. Here, the results of the 100 scrambled PCAs and the corresponding results from the original PCA based on the observed data have shown that only the first five OV values corresponding to the five first modes of the MWS are found to be significant at the 95\% level. Therefore, from the analysis and the Monte Carlo results, only the five first modes, accounting for $66 \%$ of accumulated variance, are considered (Table 2).

In Fig. 2a-e, eigenvectors or spatial patterns of the retained MWS PCs are shown, highlighting diverse areas of different wind behavior over Spain. The leading wind PC pattern (Fig. 2a) accounts for the most important variance percentage of the original data (37.9\%). In Fig. 2a the spatial pattern shows homogeneous wind behavior in inner Iberia, underlining the area corresponding to the North Iberian Plateau with high correlation values. This behavior in the

Table 2

Variances explained by the five first modes of the individual fields. The variance is in percent.

\begin{tabular}{lcc}
\hline PC & MWS & Z1000 \\
\hline 1 & 37.9 & 25.2 \\
2 & 11.5 & 20.1 \\
3 & 7.2 & 14.0 \\
4 & 5.0 & 9.2 \\
5 & 4.5 & 7.5 \\
\hline
\end{tabular}



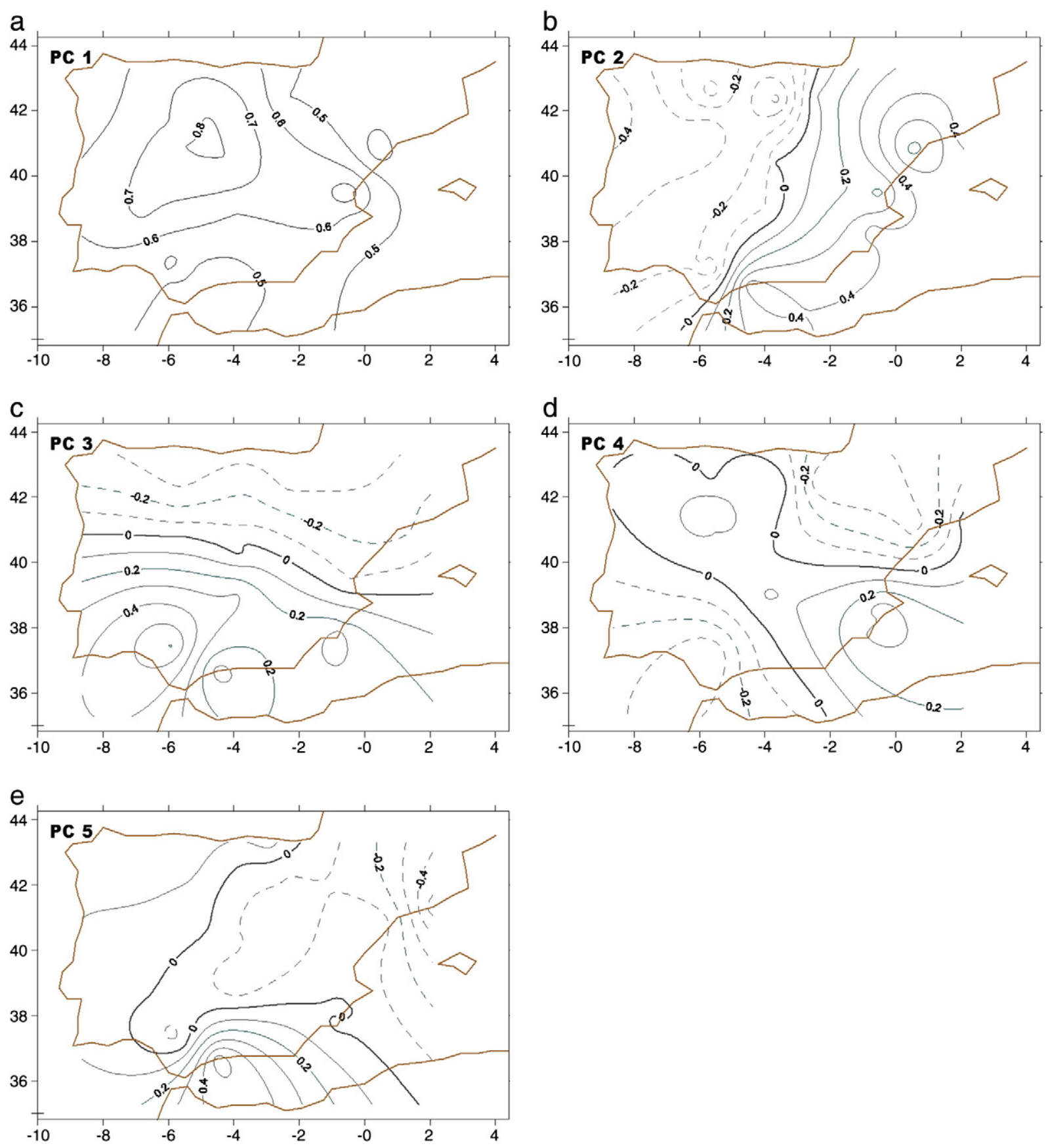

Fig. 2. Spatial patterns of the selected modes corresponding to wind speed: (a) first to (e) fifth PCs. The positive (negative) correlations are solid (dashed).

wind field could be related to the predominant westerly circulation regime (Poniente) in the Iberian Peninsula. The PC2 pattern (accounting about $12 \%$ variance) shows a westeast isoline distribution, with the highest negative loading values in western and northern Atlantic Iberia and the highest positive correlation values over some Mediterranean areas (Fig. 2b). There is a strong positive correlation nucleus over the Catalonia zone. This area typically characterizes by strong Tramontana (Font, 2000; Garcia, 1985). As it is abovementioned, the Tramontana are northern or northeastern winds affecting Catalonia and the Balearics. Moreover, the differences across the Gibraltar Strait are also remarkable. The third PC spatial pattern (Fig. 2c), accounting about $7 \%$ of total variance, shows a north-south isoline distribution, depicting high correlation positive (negative) values around the Gibraltar Strait (northern Spain). This configuration could be associated with winds blowing Iberia having north or south component. On the other hand, the PC4 pattern accounts for $5 \%$ of variance (Table 2). It is marked by isolines showing a "corridor" with two different 
zones, the northeast and the southwest areas flanking an area that covers the two Peninsular Plateaus, emphasizing the Spanish Mediterranean area centered on Valencia Cost (Fig. 2d). Finally, the wind PC5 pattern (Fig. 2e) is mainly characterized by high positive correlation values in the east of the Gibraltar Strait. This situation is associated to the
Strait channeling effect, which determines different behavior over the area.

The time variability of the spatial patterns above described is depicted showing the evolution of the first five PC time series obtained by applying the PCA over the MWS data in wintertime. Fig. 3 shows the evolution of the leading
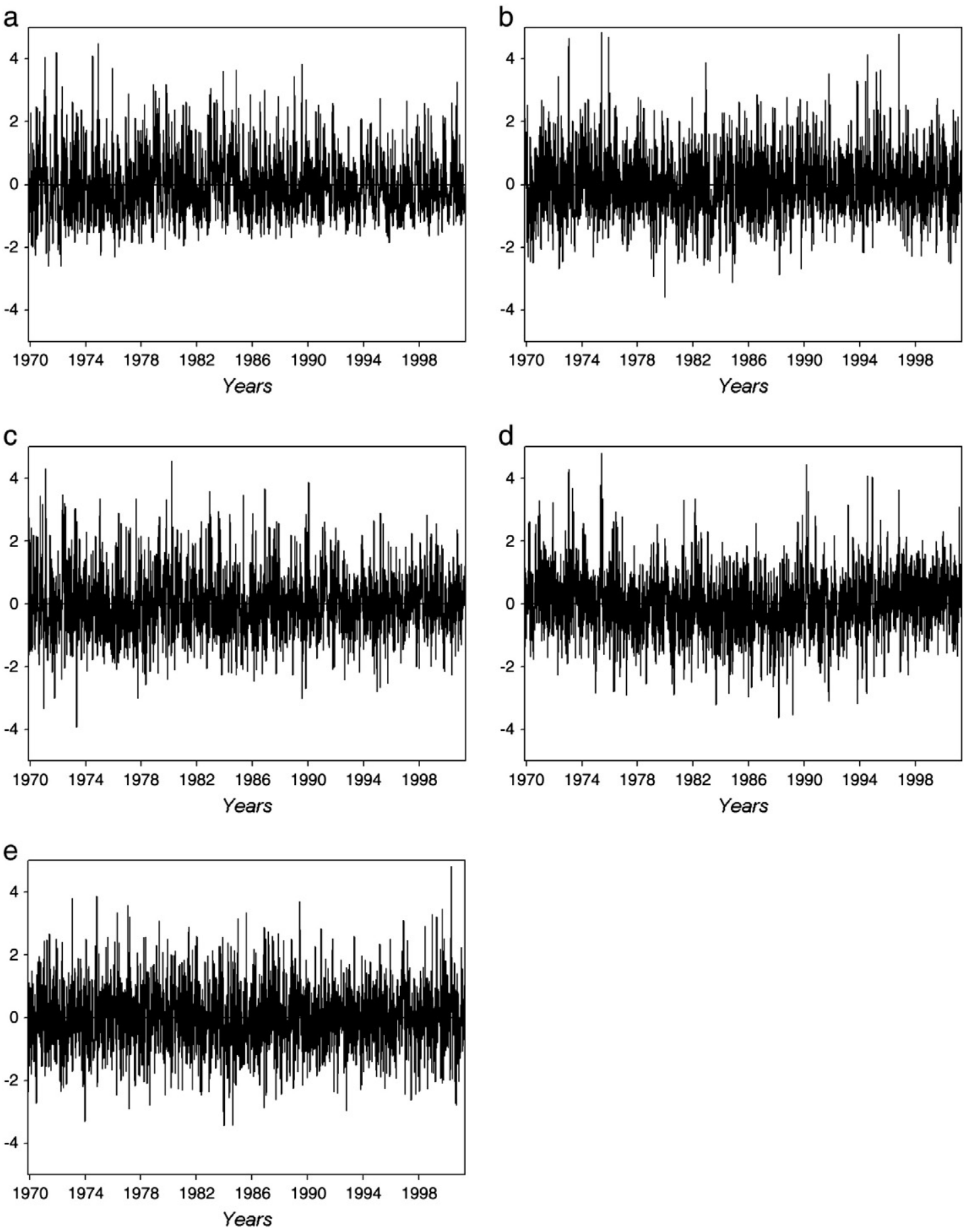

Fig. 3. Time series of: the first (a) to the fifth (e) principal component of the wind speed. Units are in standard deviations in the $y$-axis and the $\mathrm{x}$-axis corresponds to the time period. 
five PC time series of the MWS. Significant trends are not found after applying a Mann-Kendall test and a spectral analysis of the PC time series (Goossens and Berger, 1986). As it is abovementioned the first spatial pattern of Fig. 2a showed similar wind behavior over Iberia, underlying areas corresponding to the North Iberian Plateau. This behavior

a

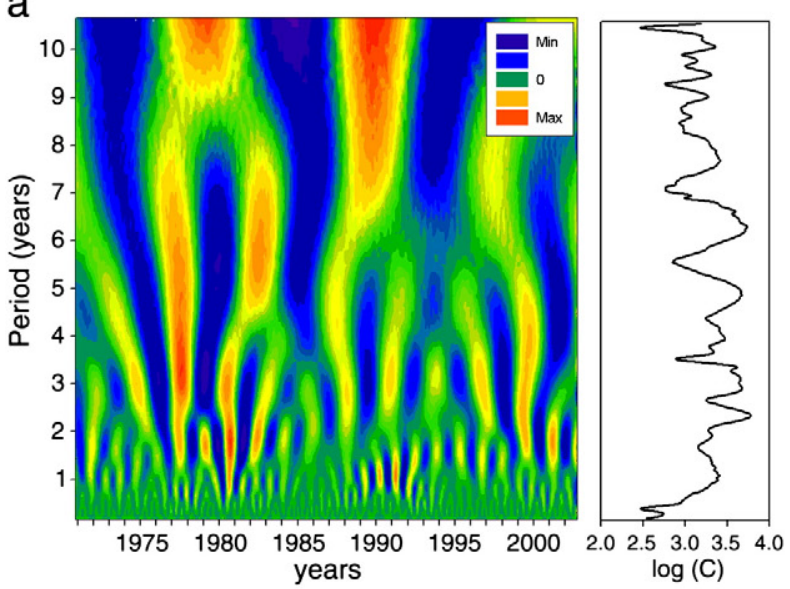

C

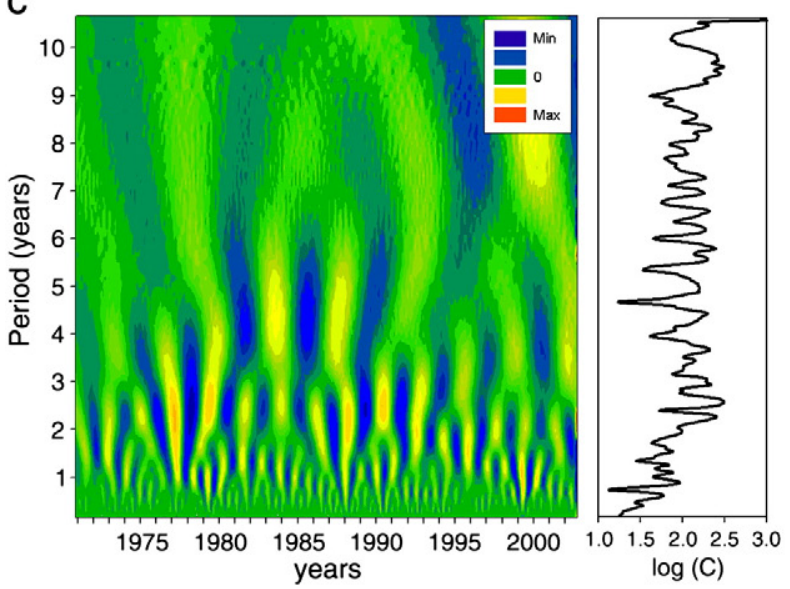

e

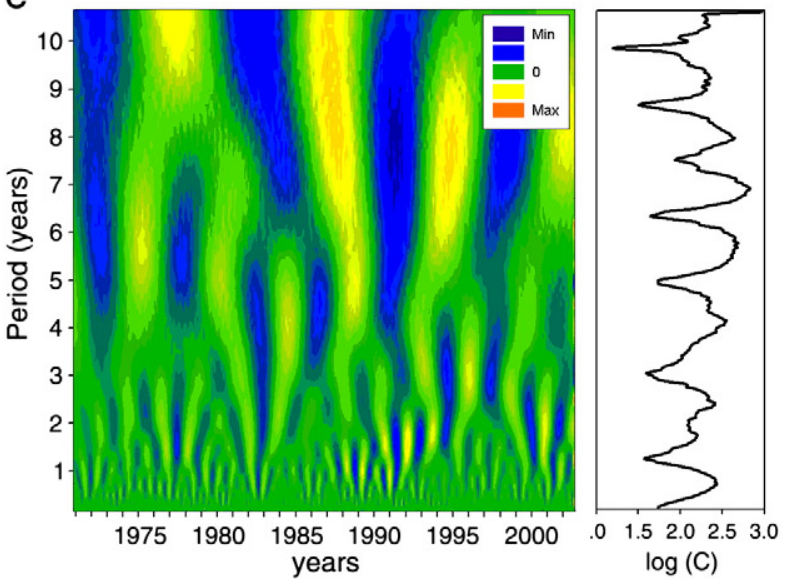

can also be represented in the corresponding time series (Fig. 3a) with mostly positive and high score values over the selected period (1970-2001). In order to identify more detailed features, the Morlet continuous wavelet analysis is applied to the PC time series, getting more information of such time series. As it is mentioned in the previous section,

b

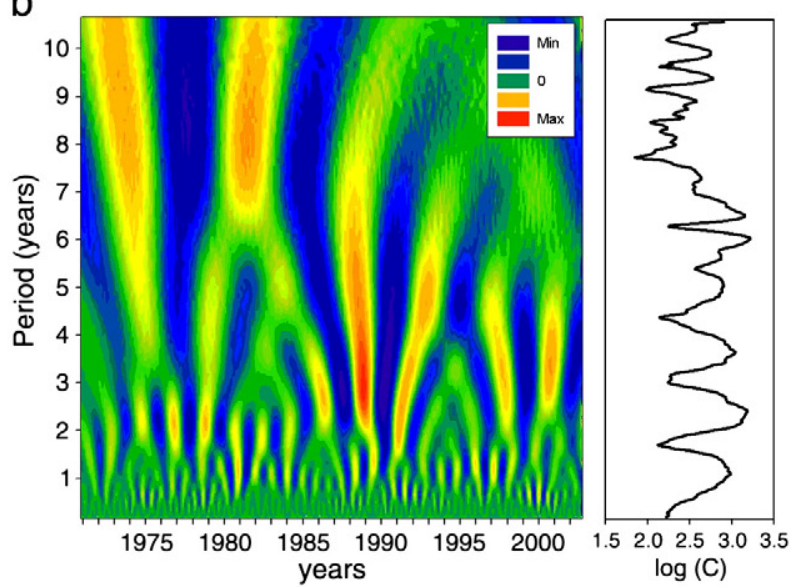

d

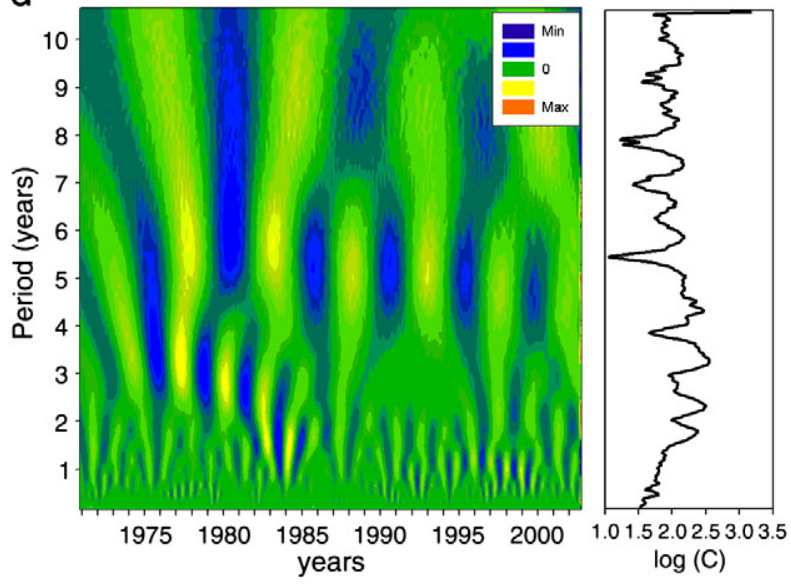

Fig. 4. Wavelet power spectra of the first (a) to the fifth (e) PC time series of the wind speed. The y-axis represents the period (years) and the x-axis corresponds to the time period (year). 


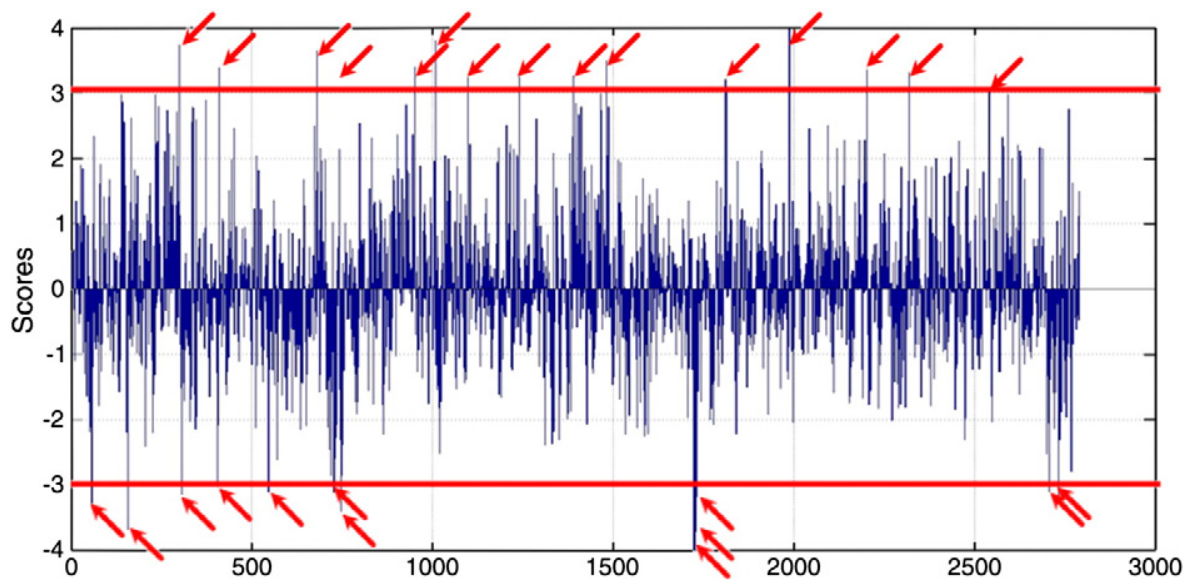

Fig. 5. Illustration of picked up dates from the PC time series. Red rows indicate both the $5 \%$ high positive and negative scores used to build the composite maps.

the wavelet transformation has not only good local properties in time and frequency domain, but it also works as a microscopic analytical function by decomposing a time series into a set of scale components. Like Fourier sines and cosines, wavelets are basis functions that can be used to represent any given signal as they contain information about frequencies of the signal over all times instead of showing the frequency variations in time. In the wavelet spectrum of the first wind speed $\mathrm{PC}$, the power spectrum intensity (Fig. 4a) is mainly concentrated in periods between 3 and 8 years, with highly energetic amplitude centered around 1974 and 1986, approximately, being noticeable a maximum a

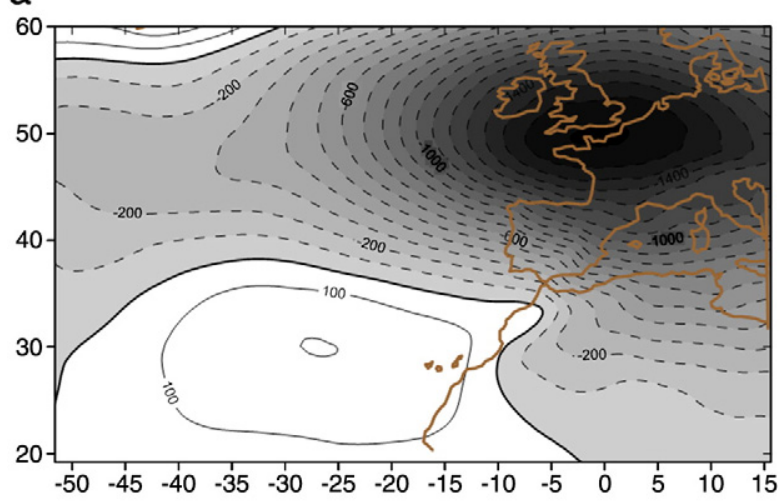

C

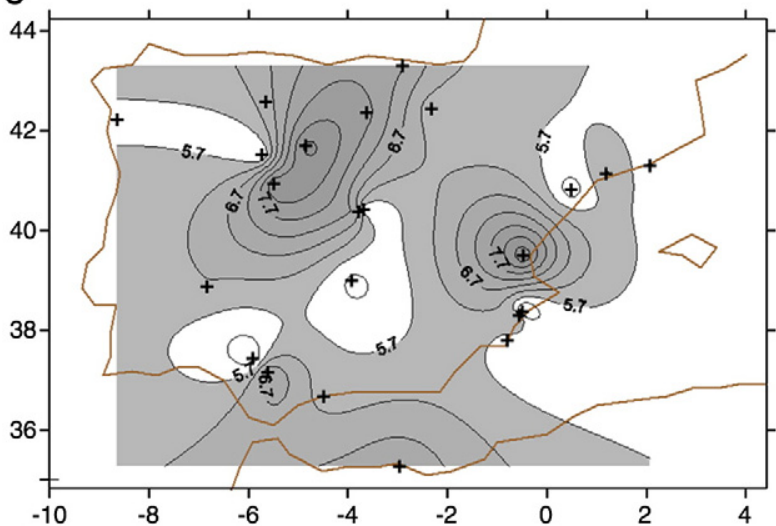

b

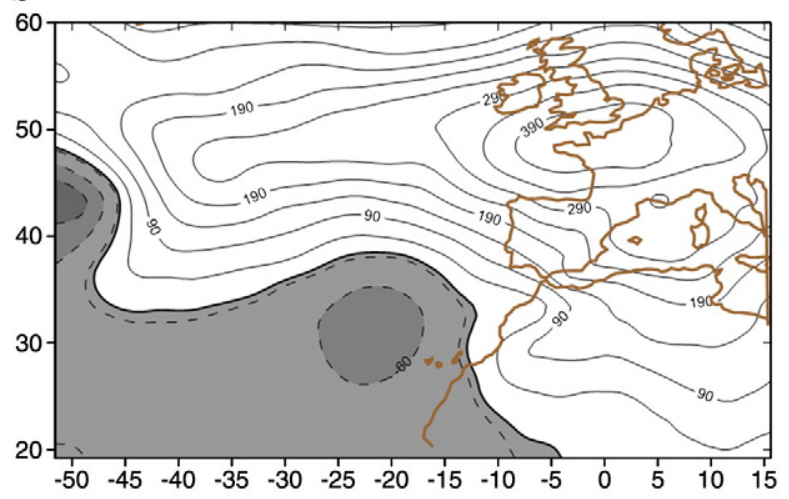

d

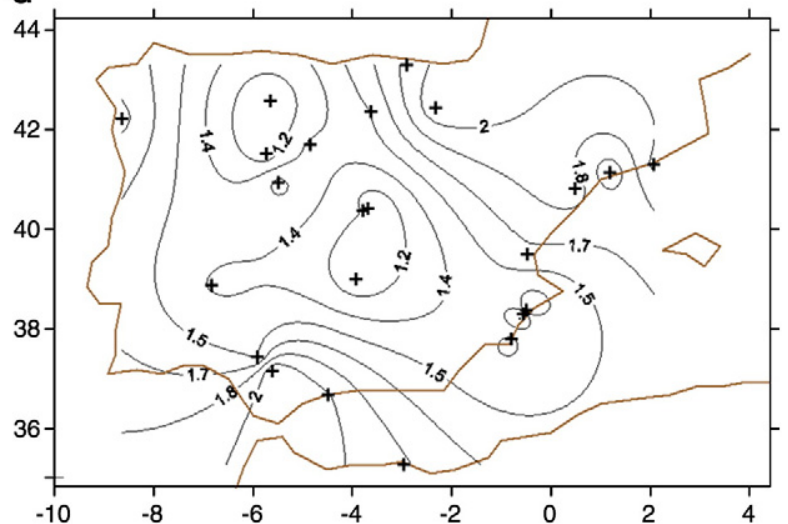

Fig. 6. Composite maps of the Z1000 (gpm) conditioned by the highest and lowest scores of the first wind speed PC: (a) positive composite; (b) negative composite. Composite maps of wind $\left(\mathrm{ms}^{-1}\right)$ : (c) positive composite and (d) negative composite with shaded areas highlighting mean wind speed higher than $5 \mathrm{~ms}^{-1}$. Crosses indicate the wind stations. 
absolute nucleus on 1975, 1980 and 1985 with a period with maximum amplitude around 6 years. There are some remarkable peaks on these time periods in the corresponding time series (Fig. 3a). Moreover, throughout the record, some episodes of quasi-biennial oscillation (QBO) are found in Fig. 4a, lasting a short time. QBO signal highly predominates during the period 1975-1985, and exhibits high intensity around 1977. This information is also seen in the marginal spectrum (right plot) with energetic oscillations that can be observed from 2 year period to 8 year period. Moreover, periodogram of the first time series (not shown) agrees with the variability associated with low frequency periods, showing significant variance in low frequency, and considerable variance associated with higher frequency ( $<3$ years). The wavelet spectra of the remainder that obtained PC time series of the wind field show a decrease in their wavelet power spectrum signals (Fig. 4b-e). In Fig. 4b, the 2nd wind speed PC wavelet spectrum displays energetic oscillations with high energetic amplitude in high periods as it can be noted in the marginal spectrum. The intensity from the start of the record till 1980 and around 1990 is remarkable. The periodgram of the second PC time series (Fig. 3b) illustrates periods about 2.5 years, coinciding with the high energetic oscillation. There also are remarkable evolution of maximum/minimum nucleus between 1977 and 1987 with maximum amplitude for frequencies higher than 5 years. The wavelet spectrum of the $3 \mathrm{rd}$ wind

a

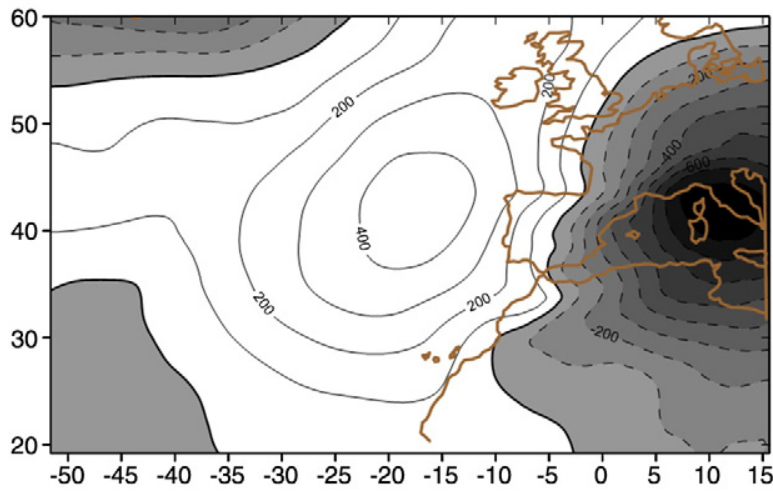

C

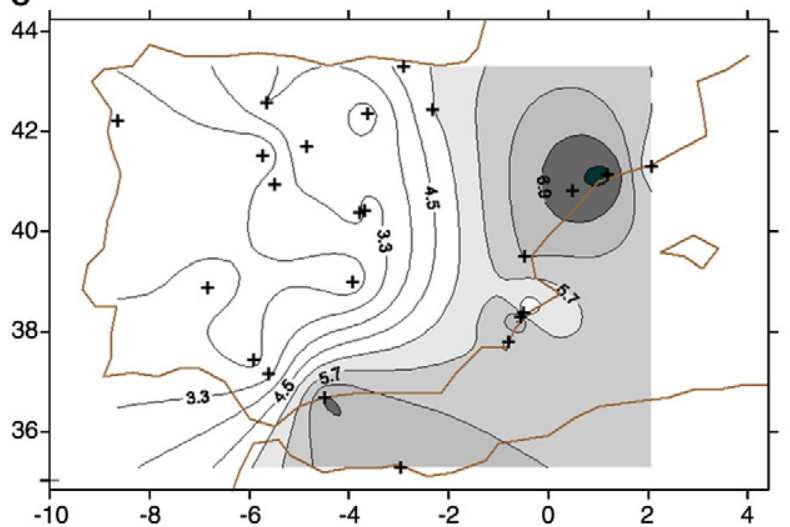

PC (Fig. 4c) depicts in general low energy, showing some energetic intensity between 1976 and 1986, with the minimum around 1980 centered on a period around 5 years, as it can be noted in the minimum of its marginal spectrum. Similar information offers the wavelet spectrum of the fourth wind PC (Fig. 4d) with absolute minima around 5 and 8 years and some energetic oscillation around 3 year-period prevailing between 1975 and 1982. Although the fifth wind PC presents the smallest variance, it is worth to note its wavelet spectrum (Fig. 4e), showing energetic intensity in all periods. Minimum intensity associated with low frequency ( $>8.5$ years) and high energetic oscillations between 5 and 8 years is remarkable, showing energetic maxima between 1982 and 1996. As in the previous time series, derived periodgrams of the remainder time series (not shown) agree with the variability found in the wavelet spectra and are associated with both low and high frequency periods.

\subsection{Z1000 observational pattern-MWS statistical mode relationships}

To examine the real atmospheric circulation features associated with the winter wind speed patterns a set of positive and negative composite plots (of Z1000 and MWS) was constructed from the dates associated with 5 and 95 percentiles of the scores of the time series obtained from the

b

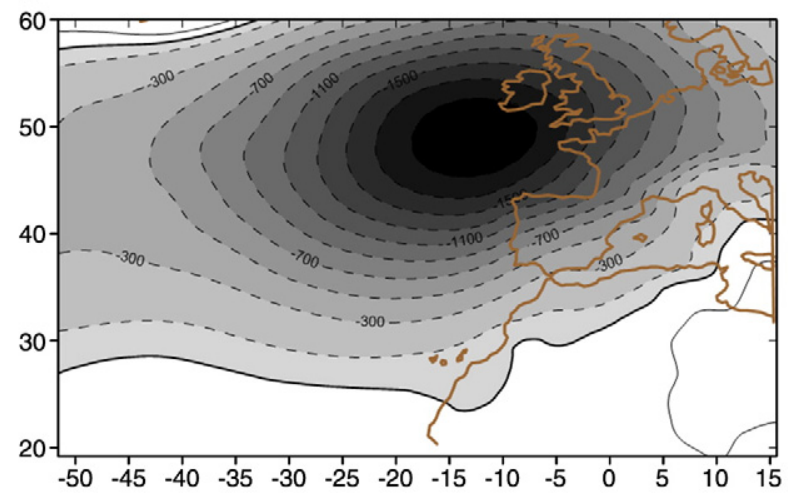

d

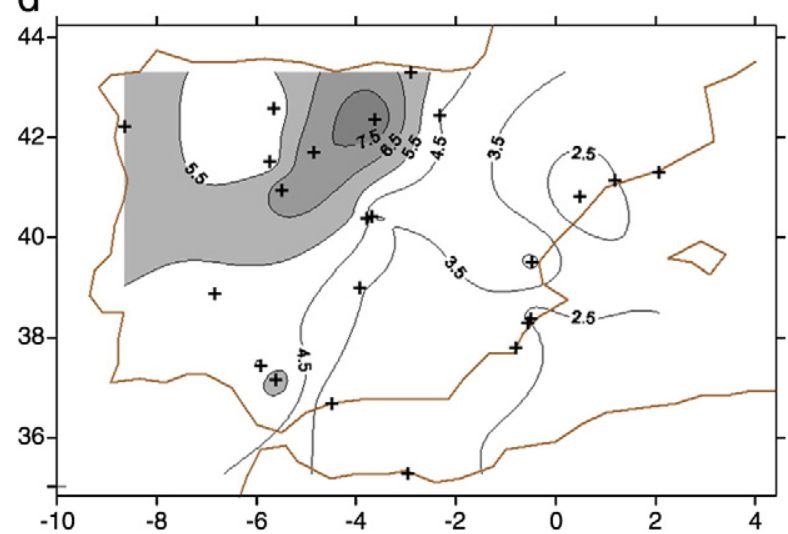

Fig. 7. Same as Fig. 6 but for the second wind speed PC. 
PCA. While the derived PC modes are statistically obtained, the composite maps represent configurations of the variable which are comparable to observations. Composites are defined here as the averaged ensemble of sets of maps of the large-scale atmospheric variable and the wind speeds. The distinctive features in the composite plots take into account the physical realism obtaining additional information to the statistical meaning of the derived spatial modes. In this paper, anomaly composites of large-scale atmospheric variables have been built for those weather configurations associated with the highest and lowest PC scores of the wind speed (Fig. 5). Thus, the composites represent the atmospheric state associated with particular extreme wind characteristics. Positive (negative) composites are constructed directly from a number of configurations with high (low) scores of the PC time series because they indicate situations in which the corresponding PC mode is dominant in its positive (negative) phase. The selected number of configurations represents $5 \%$ of the total number of cases in the data set.

Figs. 6-10 show the anomaly composites for Z1000, displaying the positive and negative composite plots conditioned by the $5 \%$ highest and lowest PC scores of the MWS (see Fig. 3). Subsequently, mean maps of Z1000 anomalies are drawn up from these days, which highlight the mean atmospheric state conditioned by predominant oscillation of the selected wind speed PC mode. Additionally, maps of MWS also corresponding those days are picked up to illustrate the behavior of the wind speed field over Spain in such atmospheric situations.

The Z1000 anomaly composites associated to the first wind speed PC (Fig. 6a, b first positive and negative composites) highlight two different mean atmospheric situations associated with the wind behavior. Thus, in the first positive anomaly composite (Fig. 6a), a strong gradient of Z1000 is observed over the Iberian Peninsula, underlying strong winds over the whole Spain as it can be noted in Fig. 6c. In contrast to this atmospheric situation, the first negative composite (Fig. 6b) displays high anomaly pressure over Iberia with little gradient over Iberia and a nucleus over northern France. This situation is indicative of low wind speed over most of the area (Fig. 6d). The Z1000 anomaly composites associated to the second wind PC (Fig. 7a, b second positive and negative composites) also highlight two different atmospheric situations associated with the wind behavior. Thus, in the second positive anomaly composite (Fig. 7a) it can be noted a Z1000 gradient over the Spanish area, pushing north winds over Spain with different wind behavior (see Fig. 2b) as it can also be noted in Fig. 7d, showing strong winds over Mediterranean area of Iberia. The second negative anomaly composite (Fig. $7 \mathrm{~b}$ ) reflects a a

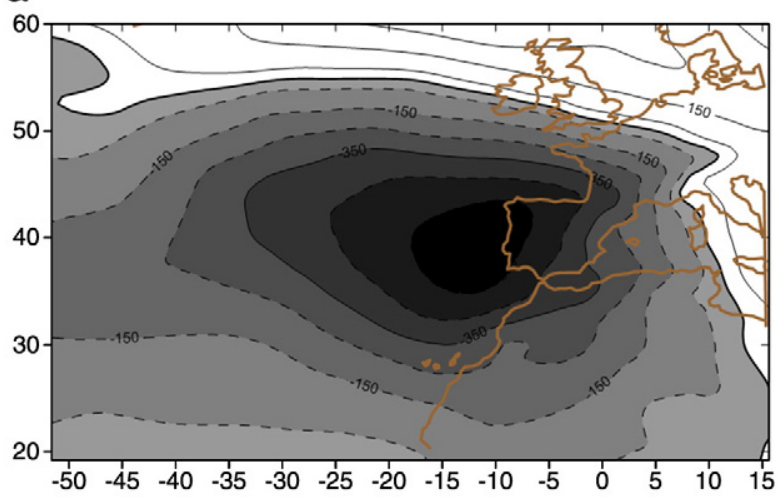

C

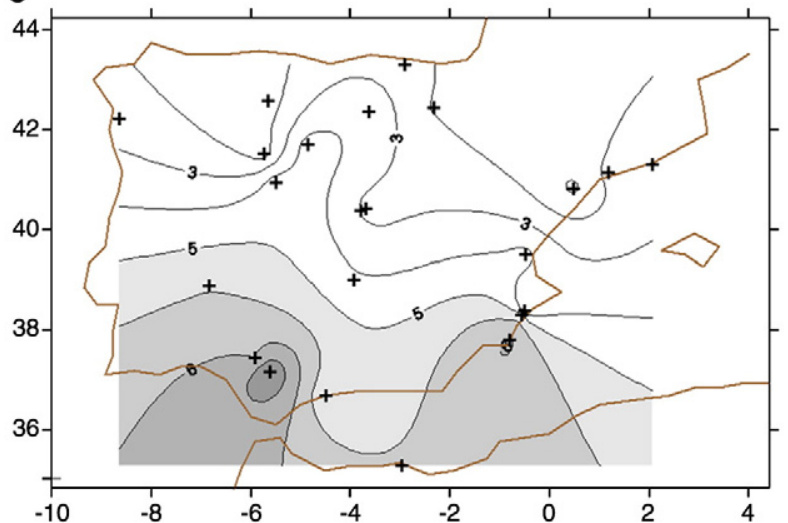

b

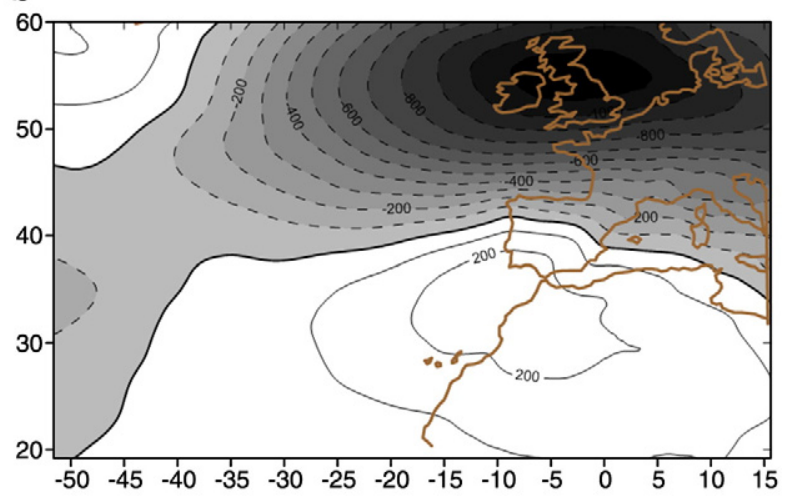

d

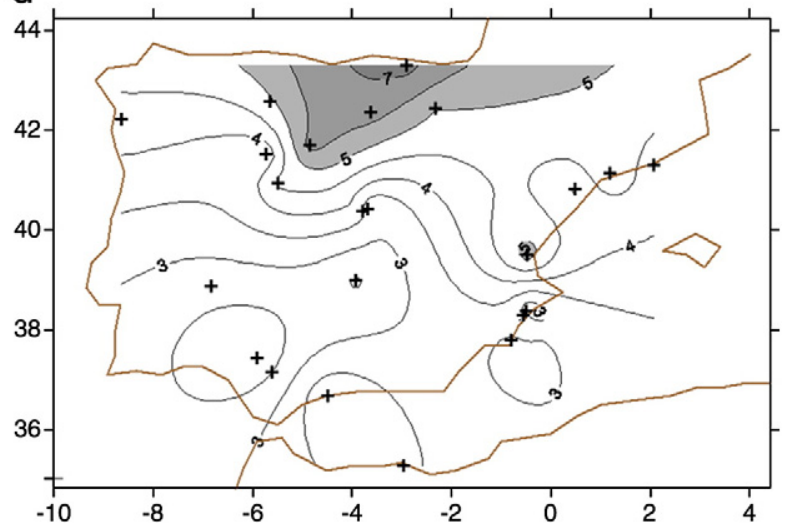

Fig. 8. Same as Fig. 6 but for the third wind speed PC. 
a

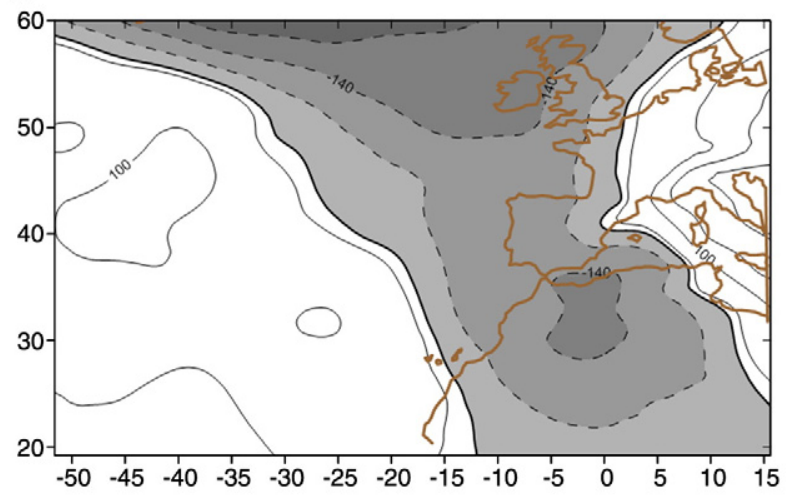

C

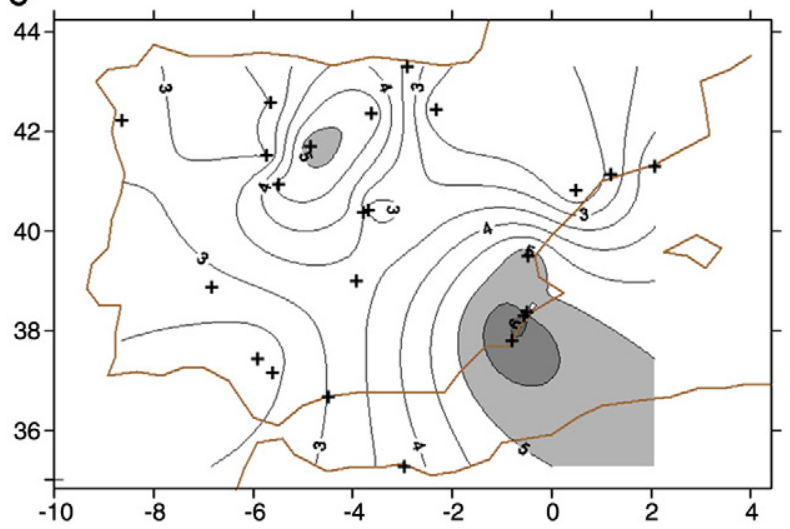

$b$

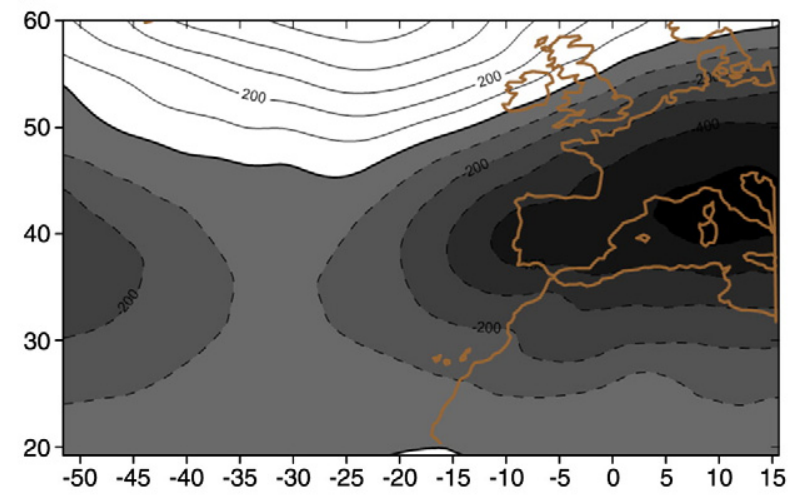

d

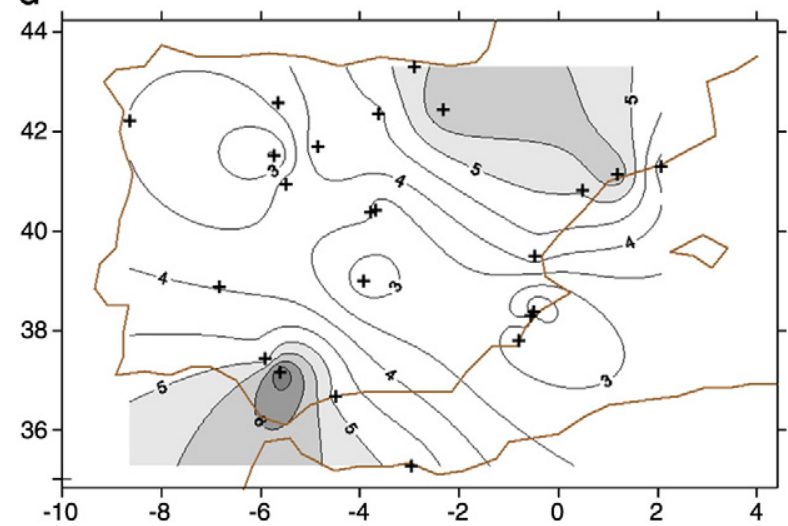

Fig. 9. Same as Fig. 6 but for the fourth wind speed PC.

configuration with a strong nucleus of negative anomalies located at western Britain, being Spain in a very strong gradient area. This configuration fosters very strong western winds blowing the Spanish area (Fig. 7d). The Z1000 anomaly composites associated to the third wind speed PC (Fig. 8a, b third positive and negative composites) underline two different atmospheric situations reflecting different behavior in the wind field over Spain. The third positive anomaly composite (Fig. 8a) shows a negative anomaly nucleus located westernward Iberia while the third negative one (Fig. $8 \mathrm{~b}$ ) depicts a high pressure area centered between Gulf of Cadiz and Canary Islands. Both situations imply differences between the northern and southern wind field as it can be observed in the Fig. $8 \mathrm{c}$ and $\mathrm{d}$ where the strong MWS are located over the Spanish southern and northern areas, respectively. The Z1000 anomaly composites conditioned by the wind speed PC4 (Fig. 9a, b fourth positive and negative composites) stand out in Fig. 9a its positive map a nucleus of negative anomalies, longitudinally extended, located over Iberia. On the contrary, the negative anomaly composite (Fig. 9b) shows a latitudinally extended zone of negative anomalies over the western Mediterranean area. With this configuration the obtained composites show wind differences between the Spanish inner respects for its northeastern and its southwestern sides are observed (Fig. 9c and d). Additionally, the Z1000 anomaly composites associated to the wind speed PC5 (Fig. 10a, b fifth positive and negative composites) also highlights two different atmospheric situations. The fifth positive anomaly composite (Fig. 10a) shows a nucleus of positive anomaly Z1000 values situated southwest of Iberia, which promotes air mass advection over the south Iberia. This atmospheric configuration favors north and northwestern winds over southern areas of Spain (see Fig. 2e), with high winds in the Gibraltar Strait area. The strong MWS displayed over the Gibraltar Strait in Fig. 10c is noticeable. On the contrary, the configuration of Fig. 10b favors the air mass advection over the Iberian Mediterranean area as it can be observed in the quite strong winds over Catalonia (Fig. 10d).

\subsection{MWS cumulated probability-Z1000 statistical mode relationships}

In this subsection, relationships between MWS and large-scale atmospheric circulation are studied by means of wind speed cumulated probabilities associated with statistical modes of Z1000. To do this, the interactions between the PCs of Z1000 (only shown some results) and the observational local MWS are provided and analyzed. Thus, plots with cumulated probability values of wind speed associated with the highest and lowest scores of the Z1000 PC (not all shown) are described. These plots provide a fair idea about the observational wind frequency distributions conditioned by the different strong scores of the PC Z1000 time series. 
a

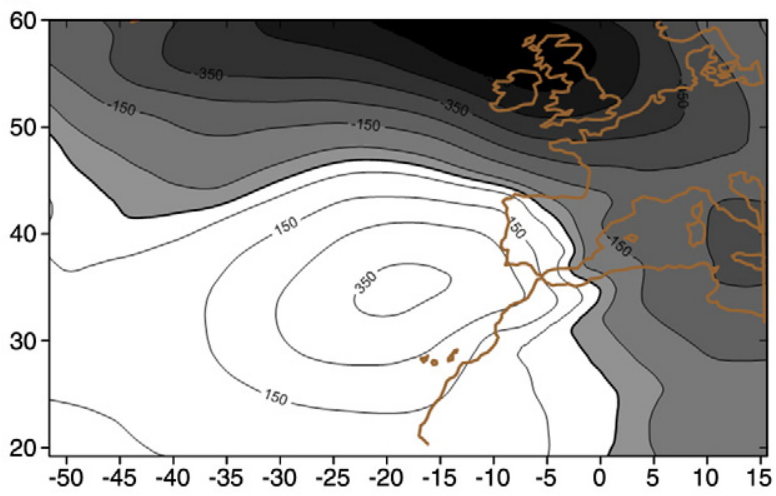

C

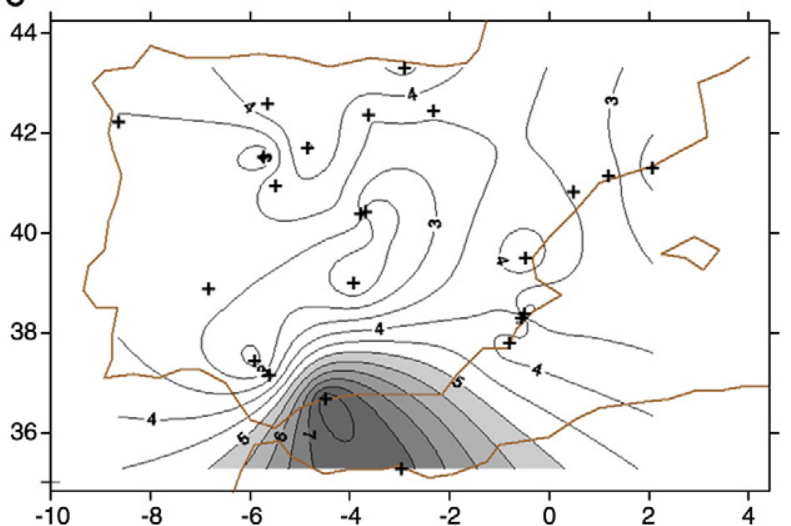

b

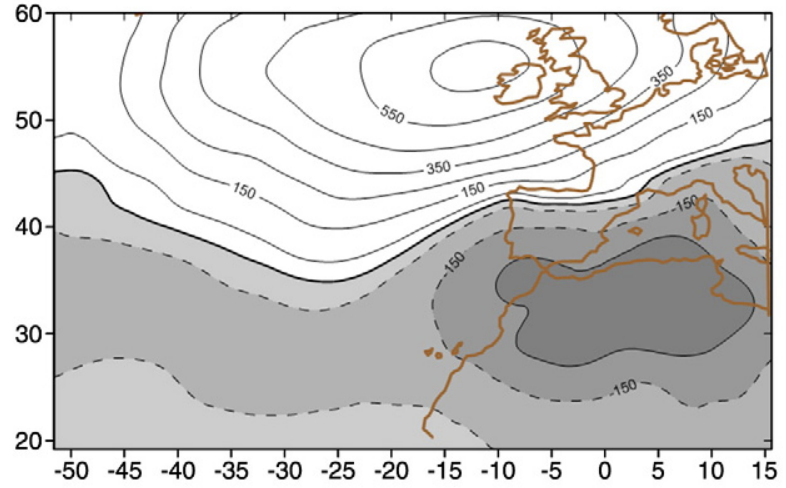

d

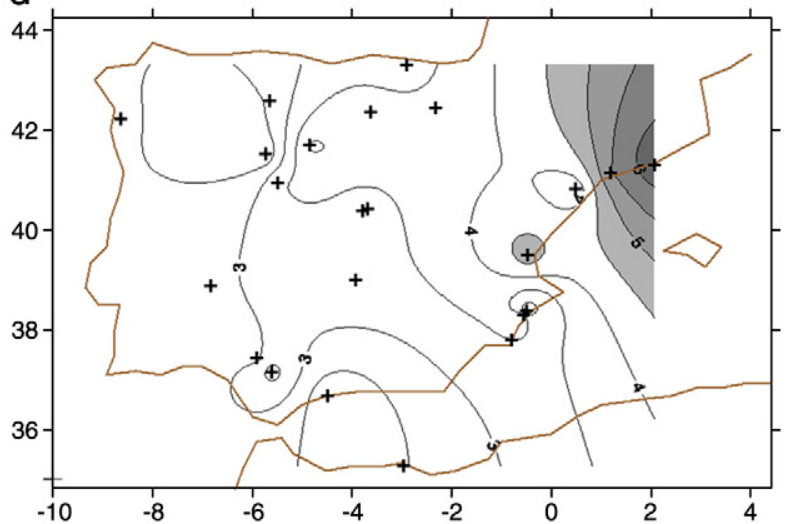

Fig. 10. Same as Fig. 6 but for the fifth wind speed PC.

In order to have an idea about the wind speed cumulated frequencies, the wind speed cumulated frequencies are derived associated to dominant positive and negative scores of the Z1000 PCs. To do this, the higher and lower Z1000 scores were selected and subsequently their associated dates. Thus, at every station, the MWS is picked up for such days, depicting the associated cumulative probabilities from 0 to $100 \%$. For brevity reasons, only the Madrid station results are shown (Fig. 11a, b). Once the PCA has been applied to the Z1000 field, the five leading Z1000 PCs, explaining 77\% of the total variability, are retained (Table 2 ). In general, the quite high mean wind speeds associated with the Z1000 PC3 are remarkable in Fig. 11a. The third most significant PC pattern obtained for the Z1000 field (Fig. 12a) consists of a configuration of positive (negative) correlation values centered over the North Atlantic area (western Mediterranean area). This isoline distribution implies that northern (southern, in its negative phase) winds are mainly affecting Iberia. Thus, such configuration is dynamically coherent and characterized by intrusions of cold (warm, in its negative phase) air masses over Iberia. This third Z1000 mode has the strongest influence over the observational wind speeds in all Spain, with daily MWS up to $10 \mathrm{~ms}^{-1}$ in Madrid station (Fig. 11a) and reaching almost $14 \mathrm{~ms}^{-1}$ in Melilla and Valencia (not shown).

Fig. 11c, d displays the results of the cumulative probabilities (in terms of the curve area values) for all used stations over
Iberia. These maps show the leading PC in the wind speed behavior. Thus, for the high positive scores of the Z1000, the higher values of the probability curve areas correspond to the third PC (Fig. 11c). As it is abovementioned, this dominant mode showed a configuration characterized by intrusions of cold (warm, in its negative phase) air masses over Iberia. On the contrary, Fig. 11d shows the results of the dominant PCs associated with the higher probability curve area values derived from the strong negative scores of the PCs. As a result, the second PC of Z1000 (Fig. 12b) is the leading mode for the negative PC scores (see also Fig. 11b), highlighting that when high positive correlation values are located over western Britain Isles and the negative ones are located over southern Atlantic Ocean, the Spanish wind speed present mainly homogeneous behavior except for some stations in the eastern Iberian Peninsula. The nearly dominance of the PC5 in most of the Spanish Mediterranean coast stations can be noted. This PC5 (Fig. 12c) presents, in its positive phase, a spatial pattern similar to the second mode except for the center of negative anomalies is located in between two strong nuclei of positive ones. The isolines are longitudinally extended which represents strong southern (northern, in its negative phase) air advection over Iberia. In its negative phase, this situation resembles an omega blocking situation (Bluestein, 1993). This persistent and particular configuration reflects a blocking pattern named 'Omega block' with a 
a

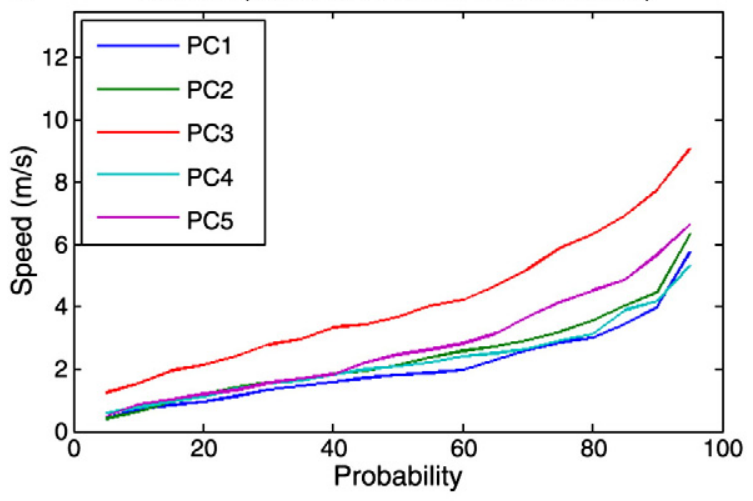

C

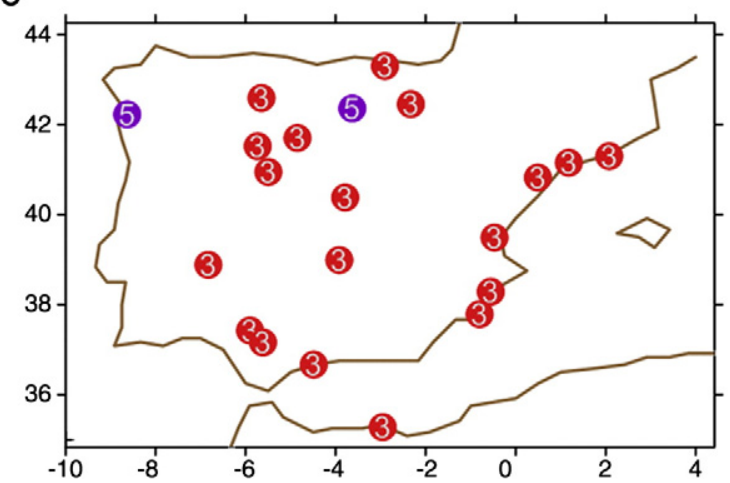

b

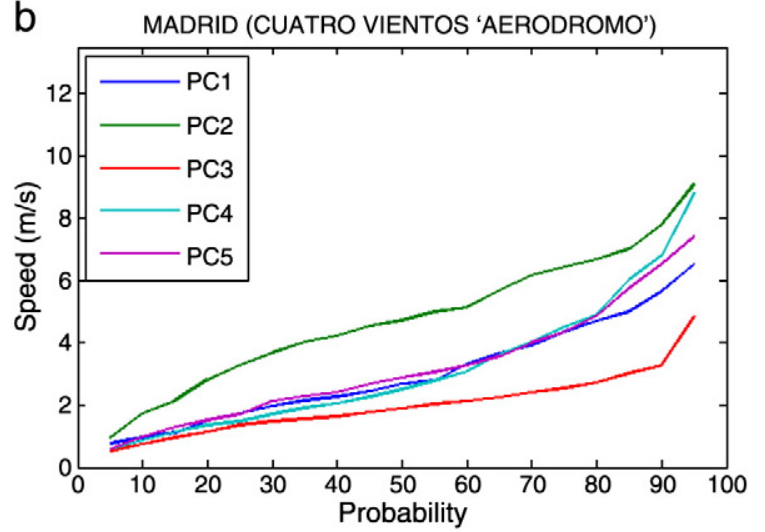

d

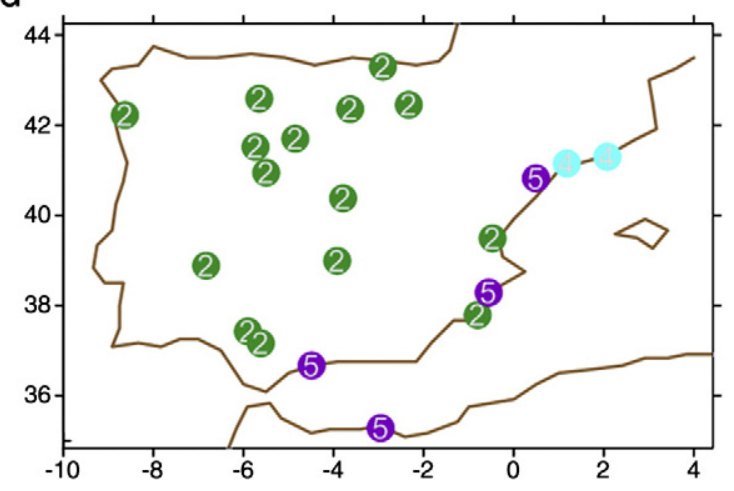

Fig. 11. Wind speed cumulated frequencies associated with the strong (a) positive and (b) negative scores of the Z1000 principal components for the Madrid station. Dominant PCs (in numbers) over stations obtained from the higher area values of the wind speed cumulated frequency curves for (c) positive and (d) negative PC scores.

meridionally oriented configuration of a high sandwich in between two lows (Bluestein, 1993). At upper level, this kind of configuration can usually be characterized by a stationary ridge laying eastern Atlantic Ocean and by a main trough situated over the western Mediterranean zone which promotes longitudinal incursions of maritime cold air which comes from high latitudes and flows into the Western Mediterranean area after rotating around a cut-off low nearby the Iberian Peninsula. In the region of the block, the weather remains essentially unchanged, as any transient weather disturbances are forced to circumvent the block. Once established, major blocking situations tend to persist for at least a week and appear to represent some quasiequilibrium state of the atmosphere. Therefore, the PC5 configuration presents a correlation isoline gradient and shows changes in the isoline signs. Such situation promotes advection of southern (northern) air masses over the Spanish Mediterranean coast.

\section{Summary and discussion}

The linkage between observed wind speed in Spain and surface circulation patterns during the winter season has been examined by means of PCA methodology. In order to characterize the atmospheric circulation, daily Z1000 of 36 winters from 1971 to 2007 has been used. Concerning the wind speed, time series of daily MWS from the 1970 to 2002 period over 21 sites on Spain have been considered. Five leading modes for both data sets have been selected, explaining more than $66 \%$ and $77 \%$ of the total variability for MWS and Z1000, respectively. The obtained MWS modes have been explained in terms of both spatial and temporal results.

Since the derived MWS PC modes are statistically obtained, the relationship between the real atmospheric circulation and the wind speed PC patterns has been analyzed by means of anomaly composite maps. The anomaly composites of large-scale atmospheric variables have been built for those weather configurations related to the PC extreme scores of the wind speed. Consequently, the composites here represent the atmospheric state associated with particular extreme wind characteristics. Additionally, the wind composites extracted from the extreme wind PC scores have been also shown. The anomaly Z1000 composites associated to the first five wind PCs highlight, in general, diverse atmospheric situations associated with different wind behavior. As a result, in the diverse obtained anomaly composite maps, there are strong anomaly Z1000 gradients, atmospheric distributions or configurations associated with low or high anomaly pressure values, which favor air mass advections with different wind characteristics over Spain as 

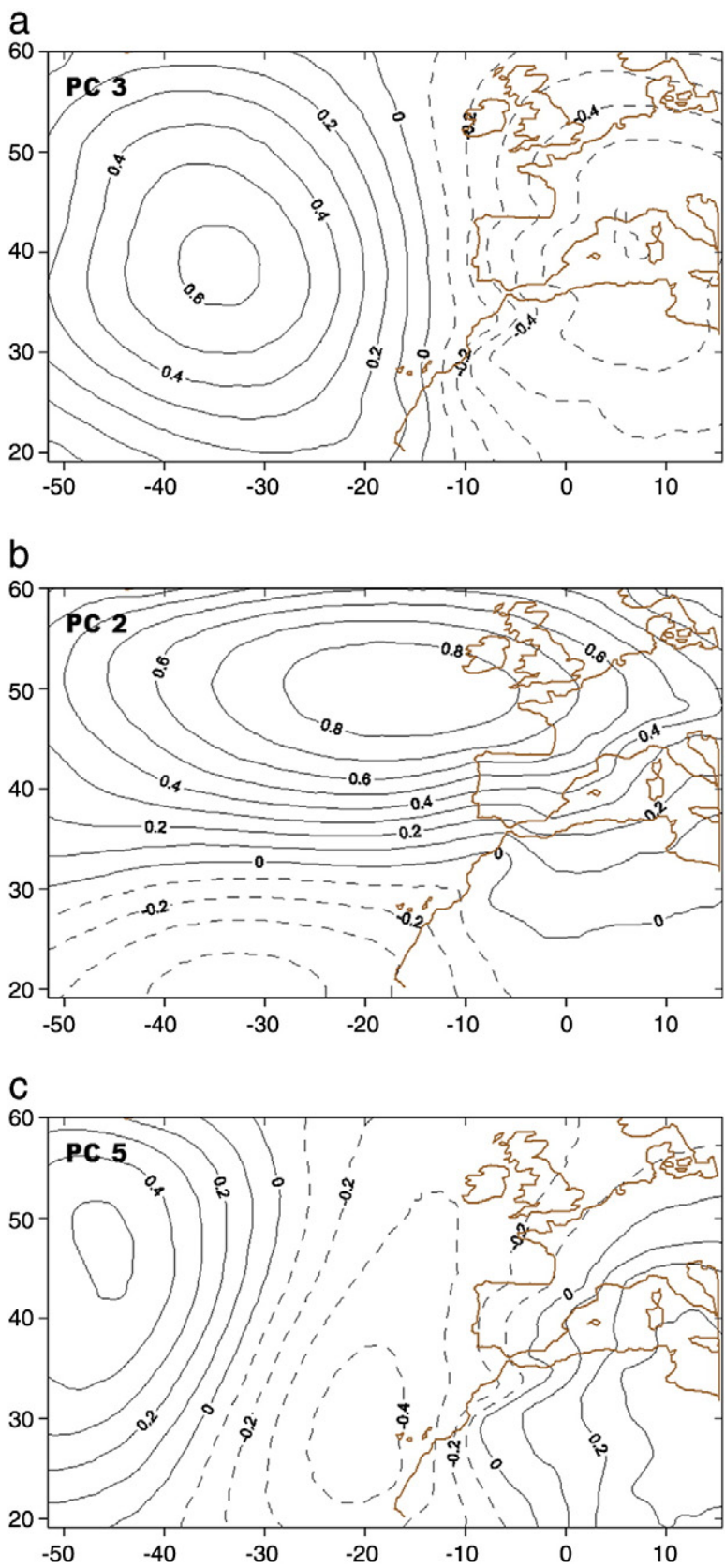

Fig. 12. Spatial patterns of the obtained modes corresponding to Z1000: (a) third PC; (b) second PC and (c) fifth PC. The positive (negative) correlations are solid (dashed).

it is shown in their corresponding wind composites. These wind maps, associated with the anomaly Z1000 composites, reflect different Spanish wind speed behaviors.

If the number of days, used for building the above mentioned composites, is compared with the obtained wavelets of such time series, some conclusions can be obtained. Fig. 13 displays wavelets (upper panel) and the number of days corresponding to the positive composites minus those corresponding to the negative composites (lower panel), indicating, in that way, the dominance of the positive score corresponding to the 95 percentile against the negative one corresponding to the 5th percentile. As an example, such differences are shown for the first two PCs of the MWS. Thus, for the first MWS PC, an area with high intensity for frequencies around 3 years between 1977 and 1984 can be noted in its wavelet spectrum. Such variability can be also observed in the lower panel of Fig. 13a, showing between the same years, an evolution of maximum $/ \mathrm{mini}-$ mum composites matching up 3 years. It is also remarkable how the power spectrum shows high energetic amplitude from the beginning of the record till 1977 and from 1985 till the end of the record for frequencies higher than 6 years, revealing also such waves in the evolution of the date composite differences (Fig. 13a, lower panel). In a similar way, for the second MWS PC, the time period between 1985 and 1992 with high intensity in the wavelet spectrum corresponding to frequencies around 4 years can be noted, as it can be also observed in the date composite differences, highlighted by the red lines in lower panel of the Fig. 13b. Moreover, it is remarkable how waves associated with low frequencies, displayed in the evolution of the composite bars in Fig. 13b, are in agreement with low frequency periods in the first part of the time record.

In this paper, additionally, relationships between MWS and large-scale atmospheric circulation are studied by means of wind speed cumulated probabilities associated with statistical modes of Z1000. Plots with cumulated probability values of wind speed associated with the highest and lowest scores of principal components of Z1000 are analyzed, giving, by means of different strong scores of the PC Z1000 time series, an idea about their conditioned observational wind frequency distributions. Thus, wind speed cumulated frequencies in every station are derived associated to dominant positive and negative scores of the Z1000 PCs. Relationships between the high wind speeds and the different PC of Z1000 are obtained. Moreover, cumulative probabilities in terms of the curve area values for all stations in Spain are derived, showing the leading PC in the wind speed behavior. As a result, for the high positive scores of the Z1000, the higher values of the probability curve areas correspond to the third PC, showing a configuration characterized by intrusions of cold (warm, in its negative phase) air masses over Iberia. For the high negative scores, the second PC of Z1000 has been revealed as the leading mode, underlining a homogeneous behavior in the Spanish wind speed when high positive correlation values are located over western Britain Isles and the negative ones are located over southern Atlantic Ocean, except for some stations in the eastern Spanish area. On the other hand, the fifth Z1000 PC is the dominant in the most of the Spanish Mediterranean coast stations, resembling its spatial pattern an Omega block situation.

The analyses have revealed the strong influence of the pressure centers over the Atlantic Ocean in the Spanish wind speed field, identifying different atmospheric circulation patterns that govern the wind speed variability at Spain during the winter season. The PCA, as well as the associated analyses based on composites and wind speed cumulated probabilities and their curve area values, have shown that the atmospheric dynamics in the North Atlantic is responsible for much of the Spanish wind speed variability. The variation of intensity and/ or position of pressure centers, within a climate change scenario, could possibly change the relative frequency of the large-scale atmospheric patterns or form new ones, changing the present wind regime. 
a

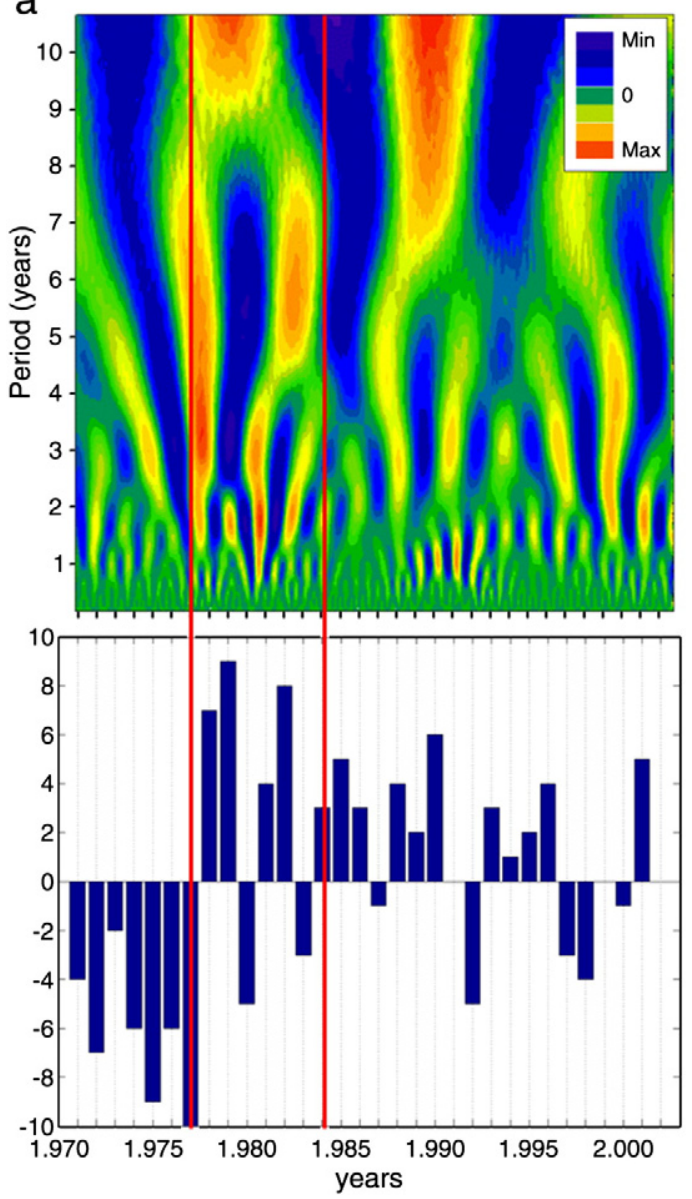

b

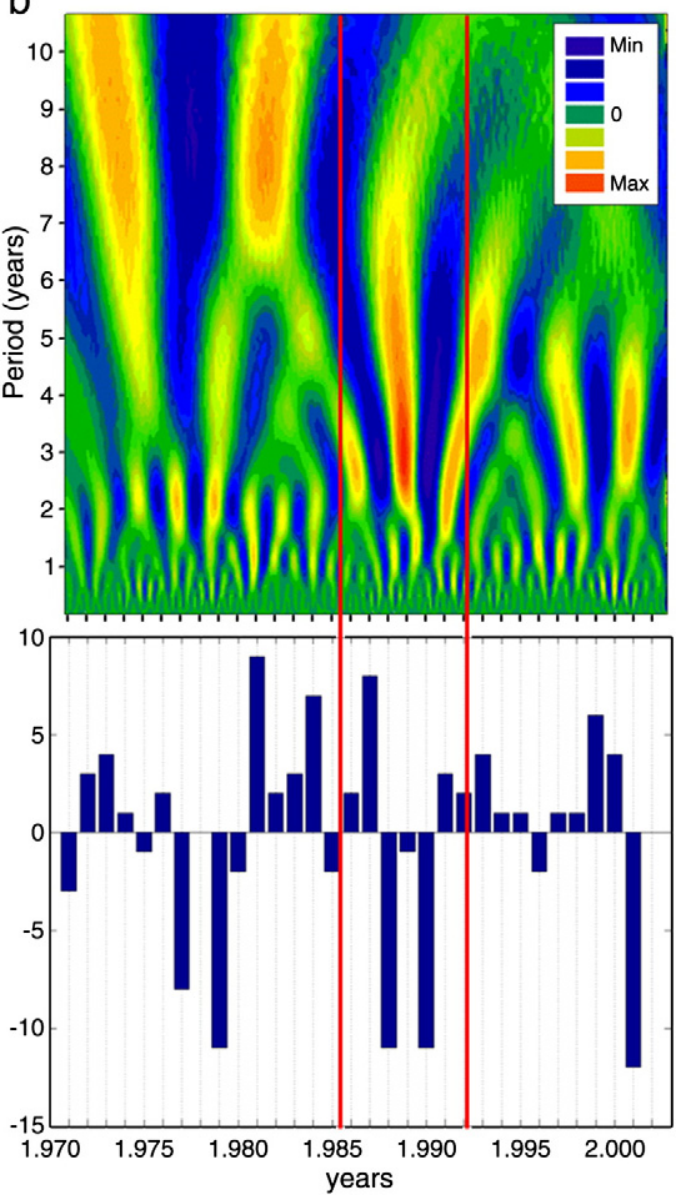

Fig. 13. Wavelet power spectra (upper panel) and the number of days corresponding to the positive composites minus those corresponding to the negative composites (lower panel) of (a) the first and (b) the second PC time series of the wind speed.

\section{Acknowledgments}

This work has been partially supported by the research projects AYA2011-29967-C05-02, UE Safewind G.A. No. 21374, VA025A10-2 and CGL2011-25327. The authors wish to thank the Spanish Meteorological Agency (AEMET: Agencia Estatal de Meteorología) for providing the Spanish wind data sets and the European Centre for Weather Medium Forecast (ECWMF) for providing the ERA40 data.

\section{References}

Amaro, J., Aran, M., Barberia, L., Llasat, M.C., 2009. The strong wind event of 24th January 2009 in Catalonia: a social impact analysis. Proc. 10th EGS Plinius Conference, Barcelona, Spain.

Aznar, R., Sotillo, M.G., Martín, M.L., Somot, S., Valero, F., 2010. Comparison of model and satellite-derived long-term precipitation databases over the Mediterranean basin: a general overview. Atmos. Res. 97, 170-184.

Bluestein, H.B., 1993. Synoptic dynamic meteorology in midlatitudes. Observations and Theory of Weather Systems, vol. II. Oxford University Press, p. 594.

Bougeault, P., Benech, B., Bessemoulin, P., Carissimo, B., Lar, A., Pelon, J., Petitdidier, M., Richard, E., 1997. PYREX: a summary of findings. Bull. Am. Meteorol. Soc. 78, 637-650.

Font, I., 2000. Climatología de España y Portugal, 2nd ediciones. Universidad de Salamanca, Spain, p. 422.
Frouin, R., Fiúza, A.F., Ambar, I., Boyd, T.J., 1990. Observations of a poleward surface current off the coasts of Portugal and Spain during the winter. J. Geophys. Res. 95, 679-691.

Gamage, N., Blumen, W., 1993. Comparative analysis of low-level cold fronts: wavelets, Fourier, and empirical orthogonal function decomposition. Mon. Weather Rev. 121, 2867-2878.

Gao, W., Li, B.L., 1993. Wavelet analysis of coherent structures at the atmosphere-forest interface. J. Appl. Meteorol. 32, 1717-1725.

Garcia, L., 1985. La predicción del Tiempo en el Valle del Ebro. Technical Report Serie A, № 38, INM, Madrid.

García-Ortega, E., López, L., Sánchez, J.L., 2011. Atmospheric patterns associated with hailstorm days in the Ebro Valley, Spain. Atmos. Res. $100,401-427$.

Gaya, M., Amaro, J., Aran, M., Llasat, M.C., 2008. Preliminary results of the Societal Impact Research Group of MEDEX: the request database (2000-2002) of two Meteorological Services. Proc. 9th EGS Plinius Conference, Nisosia, Ciprus.

Gibson, J.K., Kallberg, P., Uppala, S., Hernandez, A., Ñomura, A., Serrano, E., 1997. ERA description. Technical Report Re-analysis Project Report Series 1, ECMWF, Reading, UK.

Goossens, C., Berger, A., 1986. Annual and seasonal climatic variations over the Norther Hemisphere and Europe during the last century. Ann. Geophys. 4, 385-400.

Grossmand, A., Morlet, J., 1984. Decomposition of Hardy functions into square integrable wavelets of constant shape. SIAM J. Math. Anal. 15, 732-736.

Haynes, R.D., Barton, E.D., 1990. A poleward flow along the Atlantic coast of the Iberian Peninsula. J. Geophys. Res. 95, 11425-11442.

Huang, N., Shen, S., 2008. Hilbert-Huang transform and its applications. Interdisciplinary Mathematical Sciences, vol. 5, p. 311. 
Joliffe, I.T., 1986. Principal Component Analysis. Springer, New York, p. 271. Kaiser, G., 1995. A Friendly Guide to Wavelets. Birkhauser, Boston, p. 300

Luna, M.Y., Martín, M.L., Valero, F., González-Rouco, F., 2001. Wintertime Iberian Peninsula precipitation variability and its relation to North Atlantic Atmospheric circulation. In: Brunet, M., López, D. (Eds.), Detecting and Modelling Regional Climate Change and Associated Impacts. Springer-Verlag, Berlin, pp. 369-376.

Mahrt, L., 1991. Eddy asymmetry in the sheared heated boundary layer. J. Atmos. Sci. 48, 472-492.

Mallat, S., 1998. A Wavelet Tour of Signal Processing. Academic Press, p. 637.

Martín, M.L, Luna, M.Y, Morata, A, Valero, F, 2004. North Atlantic teleconnection patterns of low-frequency variability and their links with springtime precipitation in the western Mediterranean. Int. J. Climatol. 24, 213-230. http://dx.doi.org/10.1002/joc.993.

Martín, M.L., Santos-Muñoz, D., Morata, A., Luna, M.Y., Valero, F., 2006. An objectively selected case heavy rain event in the Western Mediterranean Basin: a study through diagnosis and numerical simulations. Atmos. Res. 81, 187-205. http://dx.doi.org/10.1016/j.atmosres.2005.12.002.

Martín, M.L., Santos-Muñoz, D., Valero, F., Morata, A., 2010. Evaluation of an ensemble precipitation prediction system over the Western Mediterranean area. Atmos. Res. 98, 163-175. http://dx.doi.org/ 10.1016/j.atmosres.2010.07.002.

Martín, M.L., Valero, F., Morata, A., Luna, M.Y., Pascual, A., Santos-Muñoz, D. 2011a. Springtime coupled modes of regional wind in the Iberian Peninsula and large-scale variability patterns. Int. J. Climatol. 31, 880-895.

Martín, M.L., Valero, F., Pascual, A., Morata, A., Luna, M.Y., 2011b. Springtime connections between the large-scale sea level pressure field and gust wind speed over Iberia. Nat. Hazards Earth Syst. Sci. 11, 191-203.

Morata, A., Martín, M.L., Luna, M.Y., Valero, F., 2006. Self-similarity patterns of precipitation in the Iberian Peninsula. Theor. Appl. Climatol. 85, 41-59. http://dx.doi.org/10.1007/s00704-005-0175-7.

Morata, A., Martín, M.L., Sotillo, M., Valero, F., Luna, M.Y., 2008. Iberian autumn precipitation characterization through observed, simulated and reanalysed data. Adv. Geosci. 16, 49-54 [www.adv-geosci.net/16/49/2008/].

Morlet, G.A., Fourgeau, I., Giard, D., 1982. Wave propagation and sampling theory. Geophysics 47, 203-236.

OrtizBeviá, M.J., SánchezGómez, E., Alvarez-García, F.J., 2011. North Atlantic atmospheric regimes and winter extremes. Nat. Hazards Earth Syst. Sci. 11, 971-980.

Palutikof, J.P., Kelly, P.M., Davies, T.D., Halliday, J.A., 1987. Impacts of spatial and temporal windspeed variability on wind energy output. J. Appl. Meteorol. 26, 1124-1133.

Pascual, A., Valero, F., Martin, M.L., Morata, A., Luna, M.Y., 2012. Probabilistic and deterministic results of the ANPAF analog model for Spanish wind field estimations. Atmos. Res. 108, 39-56. (doi: http://dx.doi.org/10.1016/ j.atmosres.2012.01.011)
Pinson, P., Madsen, H., 2012. Adaptive modeling and forecasting of wind power fluctuations with Markov-switching autoregressive models. J. Forecast. 31 (4), 281-313.

Pinson, P., Papaefthymiou, G., Klockl, B., Nielsen, H.Aa., Madsen, H., 2009a. From probabilistic forecasts to statistical scenarios of short-term wind power production. Wind Energy 12 (1), 51-62.

Pinson, P., Nielsen, H.Aa., Madsen, H., Kariniotakis, G., 2009b. Skill forecasting from ensemble predictions of wind power. Appl. Energy 86 (7-8), 1326-1334.

Preisendorfer, R.W., 1998. Principal Component Analysis in Meteorology and Oceanography. Elsevier Science Publishers BV, Amsterdam, p. 425.

Richman, M.B., 1988. A cautionary note concerning a commonly applied eigen analysis procedure. Tellus 40B, 50-58.

Simmons, A.J., Gibson, J.K., 2000. The ERA-40 Project Plan. ERA-40 Project Report Series No. 1. ECMWF, Reading, UK.

Sneyers, R., Vanlierde, R., Vandiepenbeeck, M., 1989. Principal component analysis of Belgian rainfall. Theor. Appl. Climatol. 39, 199-204.

Sotillo, M.G., Martín, M.L., Valero, F., Luna, M.Y., 2006. Validation of an homogeneous 41-year (1961-2001) winter precipitation hindcasted dataset over the Iberian Peninsula: assessment of the regional improvement of global reanalysis. Clim. Dyn. 27, 627-645.

Tastu, J., Pinson, P., Kotwa, E., Nielsen, H.Aa., Madsen, H., 2011. Spatiotemporal analysis and modeling of wind power forecast errors. Wind Energy 14 (1), 43-60.

Thuilleier, R.H., 1987. Real-time of local wind patterns for application to nuclear-emergency response. Bull. Am. Meteorol. Soc. 68, 1111-1115.

Ulbrich, U., Fink, A.H., Klawa, M., Pinto, J.G., 2001. Three extreme storms over Europe in December 1999. Weather 56, 70-80.

Valero, F., Luna, Y., Martín, M.L., 1997. An overview of a heavy rain event at Southeastern Iberia: the role of the large-scale meteorological conditions. Ann. Geophys. 15, 494-502.

Valero, F., Luna, M.Y., Martín, M.L., Morata, A., González-Rouco, F., 2004. Coupled modes of large-scale climatic variables and regional precipitation in the Western Mediterranean in autumn. Clim. Dyn. 22, 307-323. http://dx.doi.org/10.1007/s00382-003-0382-9.

Valero, F., Martín, M.L., Sotillo, M.G., Morata, A., Luna, M.Y., 2009. Characterization of the autumn Iberian precipitation from long-term data sets: comparison between observed and hindcasted data. Int. J. Climatol. http://dx.doi.org/10.1002/joc.1526. 29: 527-541.

Weng, H., Lau, K.M., 1994. Wavelets, period doubling and time-frequency localization with application to organization of convection over the tropical western Pacific. J. Atmos. Sci. 51, 2523-2541.

Zuranski, J.A., Jaspinka, B., 1996. Directional analysis of extreme wind speeds in Poland. J. Wind. Eng. Ind. Aerodyn. 65, 13-20. 